\title{
MATERIALES PARA EL ESTUDIO DE LA JURISDICCION CONSTITUCIONAL
}

\author{
POR \\ JAIME NICOLAS MUNIZ \\ RICARDO BLANCO CANALES
}

\begin{abstract}
SUMARIO
Nota PReliminar.-1. Estados Unidos: I. Colecciones de sentencias; II. Otras publicaciones; III. La jurisprudencia del Tribunal Supremo en las revistas jurídicas; IV. Obras de referencia. Materiales.-2. Austria: I. Colección oficial; II. Repertorios analíticos; III. Otras publicaciones.3. República Federal de Álemania: I. Colecciones de sentencias; II. Repertorios analíticos; III. Comentarios de la ley reguladora del Tribunal Constitucional Federal; IV. Otras publicaciones. Revistas jurídicas; V. Materiales. Obras de consulta; VI. Jurisdicción constitucional en los länder; VII. Historia: Staatsgerichtshof (Weimar).-4. ITALIA: I. Publicaciones oficiales; II. Colecciones privadas; III. Repertorios analíticos; IV. Obras de referencia; V. Jurisdicción constitucional en el plano regional.-5. Francra: I. Publicaciones oficiales; II. Publicaciones en revistas especializadas; III. Otras colecciones y repertorios.-6. EsPaña: I. En la Constitución de 1931: Disposiciones legales; Nombramiento de vocales, presidentes, constitución y sede del Tribunal de Garantías; Jurisprudencia; Bibliografía. II. En la Constitución de 1978: Disposiciones legales; Nombramiento de magistrados, constitución y sede del Tribunal Constitucional; Jurisprudencia; Comentarios de sentencias; Bibliografía: Aspectos generales, Control de constitucionalidad, Cuestión de inconstitucionalidad, Conflictos de competencia, Protección de derechos fundamentales y libertades públicas.
\end{abstract}

\section{NOTA PRELIMINAR}

La finalidad de la presente recopilación de materiales sobre la jurisdicción constitucional es exclusivamente documental. Se explica así el criterio seguido a la hora de seleccionar las obras incluidas, ya que sólo se ha dado cabida a fuentes en sentido estricto, esto es, a obras de valor informativo, no a obras de carácter exclusivamente doctrinal. No se trata, pues, de una bibliografía general sobre la jurisdicción constitucional de los países seleccionados, pretensión que sería imposible de todo punto dado el volumen de lo que se ha escrito sobre el particular en todos los países incluidos y que, en cualquier caso, puede localizarse en los respectivos repertorios bibliográficos jurídicos.

La selección de los países considerados no responde a un criterio puramente 
académico. Así, junto a países que, como Austria, Ia República Federal de Alemania e Italia, cuentan con una institución -el Tribunal Constitucional- a la que se atribuye específica y exclusivamente la función de la jurisdicción constitucional, se han incluido también materiales sobre el Tribunal Supremo norteamericano y el Consejo Constitucional francés, instituciones de articulación y naturaleza bien distinta a la de los Tribunales Constitucionales europeos, pero cuya aportación al control de la constitucionalidad de las leyes tan insoslayable resulta para el estudioso. Nadie ignora, en efecto, la significación histórica del juez Marshall, ni la línea de desarrollo seguida por el Consejo Constitucional en los últimos tiempos. La ordenación de los países incluidos responde a un criterio cronológico, habiéndose considerado relevante el inicio de las actividades de la institución respectiva.

Independientemente de las fuentes relacionadas en cada capítulo, es imprescindible la consulta de otras de carácter internacional o general como el Boletín de Jurisprudencia Constitucional, editado desde 1981 por el Servicio de Estudios de las Cortes Generales, al que se alude más específicamente en el capítulo dedicado a España, y la Europäische Grundrechte-Zeitscbrift (1974), publicación de periodicidad quincenal que, a pesar de su título, es tanto una revista de información sobre la actividad general de los diversos Tribunales Constitucionales como de tribunales y organismos supranacionales en el campo de los derechos humanos.

Gracias a una ayuda de la Fundación Juan March ha sido posible incluir el trabajo documental que aquí se presenta dentro de un proyecto más amplio integrado por un equipo en el que participan también los autores del presente trabajo. Quede constancia aquí de nuestro agradecimiento tanto a la Fundación Juan March como al resto de los compañeros que integran el equipo de trabajo.

\section{ESTADOS UNIDOS}

\section{(Tribunal Supremo)}

\section{COLECCIONES DE SENTENCIAS}

1. Colección oficial: Official Reports of the Supreme Court, usualmente: United States Supreme Court Reports. Desde 1789, con carácter oficial desde 1817.

Los noventa primeros volúmenes no se citan, sin embargo, por el título oficial, sino por la abreviatura del nombre del reporter o editor, desde 1817 nombrado oficialmente por el Tribunal. A la abreviatura del reporter o, en su caso, de la colección (U.S.) precede siempre un número, que corresponde al orden que ocupa en la serie del reporter respectivo o del conjunto de la colección a partir de 1875 . Los números que van a continuación del número de la serie y de la abreviatura corresponden a la primera página que ocupa la decisión en el volumen en cuestión.

Los primeros noventa volúmenes guardan con la serie la siguiente relación:

$\begin{array}{lrlrr}\text { Dallas } & 4(1789-1800) & \text { Dall. } & 1-4 & \text { U.S. } \\ \text { Cranch } & 9(1801-1815) & \text { Cranch o Cr. } & 5-13 \text { U.S. } \\ \text { Wheaton } & 12(1816-1827) & \text { Wheat. o Wh. } & 14-25 \text { U.S. } \\ \text { Peters } & 16(1828-1842) & \text { Pet. } & 26-41 \text { U.S. } \\ \text { Howard } & 24(1843-1860) & \text { How. } & 42-65 \text { U.S. } \\ \text { Black } & 2(1861-1862) & \text { Black o Bl. } & 66-67 \text { U.S. } \\ \text { Wallace } & 23(1863-1874) & \text { Wall. } & 68-90 \text { U.S. }\end{array}$




\section{Colecciones prividas}

a) Lawyers' Edition of the United States Supreme Court Reports (abrev. L.ed.).

Reproduce la totalidad de las sentencias de la colección oficial, acompañando el texto de un sumario de la decisión, encabezamientos e índices más completos que la edición oficial.

Mediante un sistema de star-paging remite a la paginación de la edición oficial.

Inserta en el sistema documental de los American Law Reports, de la misma editorial (Lawyers Co-opérative Publishing Company, Rochester, N. Y. Y.).

Como complemento de esta obra, Lawyers Co-op. publica una obra de referencia, el United States Supreme Court Digest Annotated, donde se prescinde del texto y se desarrollan y acumulan los índices de los volúmenes anuales del $L$. ed.

b) Supreme Court Reporter (abrev.:S. Ct.), publicado pot: West Publishing Co., Saint Paul, Min.:

Posee las mismas características que la Lawyers' Edition, pero no reproduce la totalidad de las decisiones contenidas en la edición oficial, sino que arranca del año 1882 (106 U. S.). Hasta 1980 comprendía 118 volúmenes.

Por su parte, el S. Ct. Reporter se encuentra inserto en un sistema documental propio, el National Reporter System, que trata de abarcar la totalidad de la jurisprudencia de los tribunales federales y de Estado (salvo las primeras instancias). Todos estos Reporter (uno federal y nueve, con dos series cada uno, para los tribunales de los Estados) están publicados igualmente por West.

Igual que la Lawyers' Edition, el S. Ct. lleva doble paginación, de modo que permite realizar las citas según la edición oficial. Igual también que la L. ed., lleva tablas recíprocas para con las dos otras ediciones.

Sobre la base de los índices de la colección, y con el mismo montaje que el National Reporter System, West publica un United States Supreme Court Digest, cuyos 24 volúmenes abarcan la totalidad de la jurisprudencia del Tribunal Supremo, esto es, también la de" los tomos que faltan en el $\mathrm{S}$. Ct.

\section{OTRAS PUBLICACIONES}

Además de en estas tres colecciones, las sentencias del Tribunal Supremo se publican, por imperativo legal, al día siguiente de hacerse público el fallo en unas ediciones de urgencia a cargo del Gobierno federal.

Otras ediciones inmediatas corren a cargo de empresas privadas:

- Tbe United States Law Week (The Bureau of National Affairs, Inc.).

- The Supreme Court Bulletin (Commerce Clearing House).

Por otra parte, durante el período de sesiones del T. S., a principios de cada semana, generalmente los martes, el New York Times informa acerca de las decisiones anunciadas la víspera. 


\section{LA JURISPRUDENCIA DEL T. S. EN LAS REVISTAS JURIDICAS}

Aunque la casi totalidad de las revistas especializadas analizan detenidamente la jurisprudencia del T. S. y le dedican secciones especiales, por su valor documental cabe destacar:

- el número especial que cada año (en noviembre) la Harvard Law Review dedica a la jurisprudencia del T. S., y

- la memoria anual de la evolución experimentada por el derecho en los EE. UU. (con especial atención a las decisiones del T. S., que, bajo el título «Annual Survey of American Law», publica la New York University Law Review.

\section{OBRAS DE REFERENCIA. MATERIALES}

1. Para conocer la historia y el eco de las sentencias del Tribunal Supremo en la jurisprudencia y en la doctrina científica es indispensible el recurso al sistema de los Shepards Citators.

2. Materiales importantes (formularios, normativa del Tribunal Supremo, etc.) e informaciones sobre modo de trabajo y organización se encuentran en: Robert L. Stern/E. Gressmann, Supreme Court Practice, The Bureau of National Affairs, Inc. Washington, D. C., 1976 (5.a ed.).

\section{AUSTRIA}

\section{COLECCION OFICIAL}

Las decisiones del Tribunal Constitucional se recogen en un repertorio editado por el propio Tribunal, formando una colección unitaria desde 1919 a la actualidad: Hasta 1967 inclusive: Sammlung der Erkenntnisse und wicbtigsten Bescblüsse des Verfassungsgerichtshofes; a partir de 1968 (t. 33): Erkenntnisse Beschlüsse des Verfassungsgericbtsbofes. La primera época abarca de 1919 a 1933; la segunda, desde 1946. La impresión y distribución corre a cago de la Imprenta y Editora Nacional de Austria (Oesterreichische Staatsdruckerei).

No se recoge el texto íntegro de las decisiones, sino sólo extractos muy amplios de los fundamentos jurídicos. Los antecedentes se resumen en unas pocas líneas. Cada volumen contiene un índice analítico.

Las citas de la jurisprudencia del Tribunal Constitucional se verifican siempre por la edición oficial mediante la abreviatura Slg. (Sammlung = repertorio) y el número que el asunto tiene en el repertorio (a tal efecto la numeración corresponde a una serie única y consecutiva desde el vol. I del repertorio [1919] hasta la fecha).

\section{REPERTORIOS ANALITICOS}

El mismo Tribunal Constitucional publica, a partir de la acumulación de los índices alfabéticos de la colección oficial y de los ficheros de su servicio de documentación, un repertorio analítico: Die Judikatur des Verfassungsgerichtshofes (Oest. Staatsdruckerei), del que hasta la fecha han aparecido los tres primeros volúmenes, correspondientes, respectivamente, a 1919-1964, 1965-1969 y 1970-1974. 


\section{OTRAS PUBLICACIONES}

Abstracts de las sentencias más importantes del Tribunal Constitucional y de las relativas al Derecho administrativo se publican poco tiempo después de ser hechas públicas en la Zeitschrift für Verwaltung (A. Orac. Verlag, Viena), de periodicidad bimensual.

\section{REPUBLICA FEDERAL DE ALEMANIA}

\section{COLECCIONES DE SENTENCIAS}

1. Colección oficial: Entscbeidungen des Bundesverfassungsgericbts, editado por los miembros del TCF desde 1952, en J. C. B. Mohr, Tubinga.

Se trata de una colección oficiosa, ya que la publicación oficial de las decisiones del Tribunal se verifica - sólo en su parte dispositiva- en el Bundesgesetzblatt.

No es exhaustiva de todas las decisiones del Tribunal: no se publican, salvo excepciones, los autos y decisiones interlocutorias, aunque sí la práctica totalidad de las sentencias (tanto las producidas después de vista oral [Urteile] como las producidas sin este trámite [Beschlüsse]).

Las sentencias se publican íntegras, acompañadas de un resumen (Leitsätze) preparado y aprobado por los jueces, pero que no forma parte propiamente del texto oficial de la sentencia.

Al final de cada tomo figuran unos índices de legislación y analítico, cuya acumulación da lugar, cada diez tomos, a uno de índices (Register), en el que también se insertan otros índices (de votos particulares, de normas declaradas inconstitucionales, no inconstitucionales, parcialmente constitucionales, de jueces, fe de erratas, etcétera).

Las decisiones del TCF se citan usualmente por la colección oficiosa. Para ello se emplean la abreviatura de la colección (BVerfGE) y unas cifras que indican: la primera, el número de volumen; la segunda, la página en que comienza la decisión citada, y la tercera y siguientes, si las hubiera, los pasajes específicamente aludidos.

Hasta la fecha hay publicados 59 volúmenes y cinco de índices. Los volúmenes no tienen una periodicidad fija, al objeto de que todos tengan unas dimensiones aproximadas de 450 páginas.

\section{Otras colecciones}

2.1. Giese, Schunck, Winckler (ed.), Verfassungsrechtsprechung in der Bundesrepublik, «Kommentator», Francfort M., 1956 y sigs.

Se trata de una colección de jurisprudencia constitucional que contiene también decisiones de otros Tribunales además del TCF en materia constitucional.

No publica los textos íntegros de las sentencias, aunque sí extractos literales muy amplios.

Se ordena en 34 volúmenes, más uno de índices, según el articulado de la Ley Fundamental, las constituciones de los Länder y la ley reguladora del TCF.

Sistema de hojas intercambiables. 
2.2. Otras colecciones que sólo recogen las sentencias más importantes son:

- Peter Häberle, Kommentierte -Verfassungsrechtsprechung, Athenaeum, Koenigstein/Ts., 1979.

$\because$ - Martîn Kriele, Esj-Staats und Verfassungsrecbt, C. H. Beck, Munich, 1972.

- Heinrich Scholler; Fälle und Lösungen nach böchstrichterlicben Entscheidungen, C.F. Müller, Heidelberg, 1978, 3.a ed.

- Jürgen Schwabe, Entscheidungen des Bundesverfassungsgericbts. Hamburgo, s. i., 1980.

- Christian Starck, Verfassungsrecbt in Fällen, Nomos, Baden-Baden, 1968-77.

- Hermann Weber, Rechtsprechung zum Verfassungsrecht, C. H. Beck, Munich, 1977.

\section{REPERTORIOS ANALITICOS}

1. Como complemento de esta colección, el TCF, por sí mismo y a partir de su archivo de documentación, edita un repertorio analítico (Nacbscblagewerk der Recbtsprecbung des Bundesverfassungsgericbts, publicado en cooperación por las casas Decker; Schenck y Müller, de Heidelberg, Hamburgo y Karlstuhe, respectivamente) en el que se ordenan extractos literales de decisiones y máximas jurisprudenciales (Leitsätze) según. el articulado de la Ley Fundamental, la Ley de TCF, las leyes federales y. de los Länder, el derecho zonal y de ocupación, el derecho internacional, el europeo y el público eclesiástico. La extensión máxima de las citas no suele rebasar las ocho-diez líneas.

La obra se ha comenzado a publicar por el sistema de hojas intercambiables en 1978, y aún no se ha completado la entrega básica de todos los capítulos.

2. Equiparable a un repertorio analítico, lo es en cierto modo el comentario de Leibholz y Rinck (Grundgesetz. Kommentar an Hand der Rechtsprecbung des Bundesverfassungsgerichts, Otto Schmidt, Colonia, 1979 y sigs., 6. ${ }^{\mathrm{a}}$ ed., 1130 páginas) a la Ley Fundamental sobre la base exclusivamente de la jurisprudencia del TCF, que se ordena - de modo expositivo- por el articulado del texto constitucional. Sistema de hojas intercambiables.

\section{COMENTARIOS DE LA LEY REgULADORA DEL TCF}

1. Th. Maunz, Sigloch y Schmidt-Bleibtreu, Bundesverfassungsgericbtsgesetz mit Nebengesetzen. Kommentar, Beck, Munich, 1966 y sigs. Edición en hojas intercambiables.

2. W. Geiger, Gesetz über des Bundesverfassungsgerichtsgesetz vom 12. ss. 1951. Kommentar, Vahlen, Munich, 1952, XXIII, 403 págs. Se trata del primer comentario.

3. H. Lechner, Bundesverfassungsgerichtsgesetz, Beck, Munich, 19.73, 3.a ed., 422 págs. Comentario breve.

4. Leibholz y Rupprecht, Bundesverfassungsgerichtsgesetz. Rechtsprechungskommentar, Otto Schmidt, Colonia, 1968, 568 págs: Suplemento de 1971, 158 páginas.

\section{OTRAS PUBLICACIONES, REVISTAS JURIDICAS}

Además de en el diario oficial, como ya apuntamos, las decisiones del TCF se publican con carácter inmediato y corriente entre dos y cuatro semanas después de 
ser dadas a conocer oficialmente en ciertas revistas jurídicas de periodicidad mensual o inferior. Así:

- Neue Juristische Wocbenschrift (NJW).

- Die öffentlicbe Verwaltung (DöV).

- Deutsches Virwaltungsblatt (DVB1).

La forma de citar las sentencias allí publicadas, no estando aún disponible la colección oficiosa, se basa en el número de registro del expediente judicial correspondiente (además de la cita por la propia revista).

$\because$ Para descifrar dicho número de registro valen las siguientes indicaciones sobre la base, a título de ejemplo, del siguiente número $1 \mathrm{BvF} 2 / 51$ :

$\mathrm{Bv}=$ Bundesverfassungsgericht $(\mathrm{TCF})$.

$\ll 1 »=$ Sala primera

(si fuera «2»= Sala segunda)

(si fuera asunto del pleno $=\langle\mathrm{PBv} »)$.

$\langle F\rangle=$ Procedimiento de control de constitucionalidad a instancia de un órgano constitucional (las competencias del TCF están clasificadas por letras de la $\mathrm{A}$ a la U: la $\mathrm{E}$ corresponde a conflictos interorgánicos, la $\mathrm{G}$ a conflictos de competencias entre el Estado y Regiones, la $\mathrm{R}$ a amparo, etc.).

$2 /$ = Número de asunto.

$751=$ Año en que ingresa.

(Los volúmenes de: índice de la colección oficiosa contienen una tabla de claves de registro.)

\section{MATERIALES. OBRAS DE CONSULTA}

1. Colecciones de legislación sobre jurisdicción constitucional:

- Klaus Stern, Verfassungsgerichtsbarkeit des Bundes und der Länder. Textsammlung mit Einfübrung, Heitmann, Hamburgo, $1978 \cdot y$ sigs. Contiene todos los textos normativos del TCF y de los tribunales constitucionales de los Länder. Hojas intercambiables:

2. Bibliografías:

- Mackert y Schneider, Bibliograpbie zur Verfassungsgerichtsbarkeit des Bundes und der Länder, Mohr, Tubinga, 3 vols., 1971-1976-1982. Exhaustiva de todo lo publicado sobre la materia; consigna también todas las referencias críticas, comentarios, etc., a las sentencias del TCF.

\section{JURISDICCION CONSTITUCIONAL EN LOS LÄNDER}

a) En cuanto a las leyes y reglamentos de los tribunales constitucionales regionales, remitimos a la obra ya criticada de $\mathrm{K}$. Stern; Die Verfassungsgesetze... Igualmente, Chr. Pestalozza (ed.), Verfassungen der deutscben Bundesländer mit Gesetzen über die Landesverfassungsgericbte. Textausgabe, Beck, Munich, 1978.

b) : En cuanto a las colecciones jurisprudenciales respectivas, véase Mackert y Schneider, Bibliographie zur Verfassungsgerichtsbarkeit..., epígrafes C. I-XIII. 


\section{HIȘTORIA: STAATSGERICHTSHOF (WEIMAR)}

\section{Legislación}

Texto de la ley en K. Stern, Die Verfassungsgericbtsbarkeit, cit.

\section{Jurisprudencia}

a) Publicación oficial en Entscheidungen des Reichtsgerichts in Zivilsachen, De Gruyter, Berlín, 1880-1945.

b) De consulta más accesible, Lammers y Simon, Die Rechtsprechung des Staatsgerichtshofes, Mohr, Tubinga, 2 vols.

\section{ITALIA}

\section{PUBLICACIONES OFICIALES}

1. Las decisiones del Tribunal Constitucional se publican en la Gazzeta Ufficiale della Repubblica, en edición especial (íntegtamente dedicada al Tribunal Constitucional), numerada correlativamente con el resto de los fascículos del diario oficial.

Las decisiones se publican integramente. Además, en la misma colección de la Gaceta, se incluyen los textos de los escritos de promoción de cuestiones de inconstitucionalidad.

2. El Tribunal Constitucional publica por imperativo legal una colección de decisiones: Raccolta Ufficiale delle Sentence e ordinanze della Corte Costituzionale (51 vols. hasta 1978).

Las decisiones se publican íntegras, precedidas de un encabezamiento analítico, base del índice de materias que acompaña también a cada volumen. En los volúmenes figuran asimismo índices legislativos y de partes litigantes.

En Italia, la cita de las decisiones se verifica normalmente por la colección oficial. En ella las sentencias y autos van numerados consecutivamente, iniciándose la numeración cada año.

\section{COLECCIONES PRIVADAS}

1. La más importante de las colecciones no oficiales es la de la revista Giurisprudenza Costituzionale, Giuffré, 1956 y sigs.

Se trata de una revista mixta que publica tanto los textos de las decisiones del Tribunal Constitucional y las ordenanzas de remisión de cuestiones de inconstitucionalidad como notas a las decisiones del Tribunal Constitucional y artículos científicos sobre jurisdicción constitucional.

2. Asimismo, otras revistas y publicaciones periódicas publican las sentencias del Tribunal Constitucional sin esperar a su aparición en el repertorio oficial:

- Rivista Amministrativa della Repubblica Italiana.

- Il foro Italiano. 
3. Colecciones parciales.

- Aldo Albini, Decisioni della Corte Costituzionale in Materia di Giustizia Amministrativa, Giuffré, Milán, 1967.

- Giorgio Gaja (dir.), Decisioni della Corte Costituzionale in materia internazionale, Giuffré, Milán, 1966.

- Sentenze della Corte Costituzionale in materia di famiglia (1956-1975), Giappichelli, Turín, 1975.

\section{REPERTORIOS ANALITICOS}

1. El más sistemático y extenso es:

- Repertorio delle decisioni della corte costituzionale, Ed. Giuffré (vols. publicados: 1956-67, 1968-69, 1970-71, 1972-73, 1974-75, 1976-77, e índices cronológicos: 1955-59, 1970-71, 1972-73, 1974-75, 1976-77).

La jurisprudencia del Tribunal Constitucional aparece ordenada por materias. $\mathrm{El}$ volúmen de índices es doble: a) cronológico de las decisiones, y b) del texto de los fallos.

2. Otros repertorios:

- C. Lavagna, Sistema di Giurisprudenza Costituzionale, U.T.E.T., Turín, 1963 y sigs., 2 vols. Hojas intercambiables.

- Il primo decennio di giurisprudenza della Corte Costituzionale, editado por el Servicio de Estudios del Tribunal Constitucional, Roma, s. a. Sigue la sistemática del articulado de la Constitución. Indices legislativos y analítico. Informaciones estadísticas.

- E. Naso (dir.), La Costituzione italiana nell'interpretazione della Corte Costituzionale. Commento sistematico, Edipem, Roma, 1971 y sigs., 3 vols.

- $\mathrm{Li}$ Vecchi y Boscia, Giurisprudenza completa della Corte Costituzionale, De Donato Editore, Bari, 1972, 3 vols. (1956-66, 1966-69 y 1970-71). Resúmenes de sentencias ordenadas por el articulado de los códigos y textos legales (alfabéticamente). Apéndices de normativa del Tribunal Constitucional.

- De Martino (dir.), E Costituzionale? Raccolta completa della giurispruden$z$ a della corte costituzionale sulla legislazione dello stato, Epidem, Novara, 1978-79, 5 vols., apéndice. Ordenada por grandes códigos y demás textos legales.

- A. S. Agrò y otros, La Costituzione Italiana. Annotata con la giurisprudenza della Corte costituzionale, U. T.E. T., Turín, 1979.

\section{OBRAS DE REFERENCIA}

1. Angeloni y otros, Formulario di Giustizia Costituzionale, Giuffré, Milán, 1957. Formularios y normativa del Tribunal Constitucional.

2. Battaglini y Mininni, Codice della corte costituzionale, C. E.D. A.M., Padua, 1964. Documentación parlamentaria sobre la gestación del Tribunal Constitucional. Normativa sobre jurisdicción constitucional. Indices analíticos de la doctrina. 


\section{JURISDICCION CONSTITUCIONAL EN EL PLANO REGIONAL}

1.: Alta Corte per la Regione siciliana (hasta el inicio de las actividades del Tribunal Constitucional).

a) : Repertorio de jurisprudencia: Alta Corte per la Regione siciliana. Decisioni -atti processuali- Repertorio della giurisprudenza costituzionale, editado por el Istituto di Studi giuridici e politici sulla regione «Luigi Sturzo», Giuffré, Palermo, Milán, 1956, 4 vols.

b) Decisiones del Tribunal Constitucional relativas a la región de Sicilia: Corte Costituzionale. Sentenze concernenti la regione siciliana. Atti processuali, Giuffré, Milán, 1960 , 16 vols.

c) Materiales sobre la Alta Corte: Bataglini, Codice..., apéndice, págs. 901-988.

\section{FRANCIA}

\section{PUBlicaciones oficiales}

1. Las decisiones del Consejo Constitucional se publican en texto ítitegro (y desde hace poco numeradas según el repertorio del propio Consejo) en la serie legislativa (Lois et décrets) del Journal Officiel, generalmente al día siguiente de su emisión.

2. Las decisiones y dictámenes del Consejo Constitucional se reúnen anualmente en el Recueil des décisions du Conseil constitutionnel, publicado bajo el alto patronazgo del Consejo por la Imprimerie Nationale, París (23 vols. hasta el año 1980). La confección del repertorio corre a cargo del Servicio Jurídico del Consejo.

El Recueil se estructura de la siguiente manera:

1) Textos (normativa, nombramientos, etc.).

2) Decisiones relativas a constitucionalidad de las leyes.

3) Decisiones relativas a calificación de textos de forma legislativa.

4) Contencioso electoral.

5) Otras decisiones.

6) Tablas: índice de decisiones del año correspondiente e índice analítico-alfabético, en este caso acumulativo de todos los tomos precedentes.

Las decisiones se publican íntegramente, precedidas de un breve encabezamiento indicando fecha y objeto de la decisión.

3. El propio Consejo Constitucional ha publicado igualmente en la Imprimerie Nationale dos tablas analíticas:

a) Una tabla relativa al contencioso electoral (1979, 280 págs.).

b) Una Table analytique des décisions de 1959 à 1980 (contrôle de constitutionnalité et délimitation des compétences), Imprimerie Nationale, París, 1981, 565 págs. Esta tabla, cuya información es mucho más extensa que la dada por el índice analítico-alfabético del Recueil, posee, a su vez, índices propios: alfabético (págs. 487 a 516); de textos de principios considerados en las decisiones del Consejo (págs. 519 a 531), que ofrecen un cuadro completo de las normas de referencia y de su aplicación, y cronológico de las 266 decisiones analizadas. Esta tabla está construida siguiendo en cierta manera las pautas de las tablas vicenales del Recueil Lebon.

4. La doctrina del Consejo Constitucional se encuentra automatizada en alta 
medida tanto por el CEDIJ (Centre d'Informatique Juridique) como en el fichero legislativo informatizado del secretario general del Gobierno (fichero LEX), inaugurado en abril de 1981.

\section{PUBLICACIONES EN REVIISTAS ESPECIALIZADAS}

Las decisiones del Consejo Constitucional se publican regularmente en las siguiéntes revistas especializadas:

1. Recueil Dalloz (semanal).

2. L'Actualité Juridique. Droit Administratif (mensual).

3. Juris-classeur périodique. La semaine juridique (semanal); índices analítico, de decisiones y apéndice legișlativo.

\section{OTRAS COLECCIONES Y REPERTORIOS}

La doctrina del Consejo Constitucional es accesible en una serie de publicaciones que recogen y. estudian por lo general sólo las decisiones más revelantes. Entre ellas destacan:

- Favoreu y Philip, Les grandes décisions du conseil constitutionnel, Sirey, París, 1979, 2. ${ }^{\mathrm{a}}$ ed. Texto íntegro de las sentencias seleccionadas.

- Franck, Droit constitutionnel, P. U.F., París, 1978 (Jurisprudencia constitụcional francesa del Consejo Constitucional, Consejo de Estado y Corte de Casación ordenada según el artículado de la Constitución).

- Maus, La pratique institutionnelle de la Ve République, La Documentation Française, CNRS, París, 1978 (entre otros documentos se recoge el texto de la práctica totalidad de las decisiones emitidas por el Consejo Constitucional, así como una tabla analítica sumaria de la doctrina del Consejo, según el articulado de la Constitución de 1958.

- Souty, Recueil de jurisprudence en matière constitutionnelle et de libertés publiques, Editions Domat. Montchrétien, París, 1950 (para la jurisprudencia anterior a la V República).

Para seguir la jurisprudencia del Consejo, ofrecen valiosas informaciones las crónicas constitucionales que periódicamente publican las revistas Revuue de droit publique et de la science politique y Pouvoirs. Revue française d'études constitutionnelles et politiques. De esta última revista puede consultarse asimismo su número 13 (1980), dedicado monográficamente al Consejo Constitucional, con informaciones estadísticas; biográficas y bibliográficas.

\section{ESPAÑA}

Existen en la reciente historia de España dos momentos de especial trascendencia en la preocupación por adecuar eficazmente el ordenamiento jurídico a la norma constitucional. Se trata, como es sabido, del establecimiento de una jurisdicción específicamente constitucional llevada a cabo primero pot la Constitución republicana de 1931 y en la actualidad por la de 1978. Los materiales de trabajo reunidos aquí han sido distribuidos en estos dos grandes apartados.

El problema de la constitucionalidad del ordenamiento $y$, consiguientemente, el de los modos de exigibilidad de tal adecuación. ha existido también en otros 
períodos de nuestra historia. Como primer antecedente se cita el Proyecto de Constitución federal de la República española de julio de 1873. Incluso en épocas no constitucionales, como la dictadura del general Primo de Rivera o el período franquista, hubo, paradójicamente, intentos de establecer algo parecido a un control de constitucionalidad.

Por otra parte, la defensa jurisdiccional específica de las libertades públicas se remonta, al parecer, mucho más atrás en el tiempo.

Sin embargo, y a pesar de unos y otros antecedentes, hasta 1931 no se plantea en España la existencia de una jurisdicción constitucional con las características suficientes para ser llamada asi ${ }^{1}$.

1 Cfr. Niceto Alcalá-Zamora y Castillo, «Encuesta sobre justicia constitucional», en B. I. C. Abog. Madrid, 2 (1971), y también en Estudios Procesales, Madrid, Tecnos, 1975; José Almagro Nosete, «Un precursor en España del moderno Derecho procesal constitucional: el doctor Alvarado», en Revista de Derecho Procesal Iberoamericano, XXVII, número 1 (1981), págs. 7-20; José Barragán Barragán, El juicio de amparo mexicano y el recurso de contrafuero, Valencia, Facultad de Derecho, Cátedra Fadrique Furio Ceriol, 1976; José Luis Bermejo Cabrero, "La idea medieval de contrafuero en León y Castilla», en Revista de Estudios Políticos, núm. 187 (1973), págs. 299-306; Manuel Francisco Clavero Arévalo, «Justicia constitucional y justicia administrativa: reflexiones sobre el recurso de contrafuero», en Primeras Jornadas Administrativas de Galicia, Madrid, 1970, págs. 21-50, y también en Anales de la Universidad Hispalense (1969); Víctor Fairén Guillén, Antecedentes aragoneses de los juicios de amparo, México, UNAM, 1971; «La defensa del derecho de libertad personal en la historia y en la actualidad española», en Revista de Administración Pública, núm. 69 (1972), págs. 9-58; «Respuesta a encuesta sobre justicia constitucional», en Boletín del Colegio de Abogados de Madrid, núm. 2 (1971); Recaredo Fernández de Velasco, «Las leyes inconstitucionales y la función judicial en la legislación española», en Revista de Derecho Privado, núm. 13 (1926), y en su libro Variaciones de Derecho y política, Barcelona, 1932; José María de Frutos Isabel, «Decreto-ley y recurso de contrafuero", en Estudios Homenaje al profesor López-Rodó, II, págs. 51-71; Francisco Javier Gálvez Montes, «El control de la constitucionalidad en España», en España, años setenta, III-1, págs. 1291-1370; M. García Canales, El problema constitucional en la dictadura de Primo de Rivera, Madrid, Centro de Estudios Constitucionales, 1980; Eduardo Gómez Vaquero, «El amparo, djurisdicción o recurso?», en Revista General de Legislación y Jurisprudencia (1928), págs. 114; Jaime Guasp, «La justicia constitucional en España», en I Congreso Mexicano de Derecbo Procesal, México, 1960, págs. 203-219; Gutiérrez de Cabiedes, «Respuesta a encuesta sobre justicia constitucional», en B. I. C. Abog. Madrid, 1 (1971); A. Jorge Alvarado, El recurso contra la inconstitucionalidad de las leyes, Madrid, Reus, 1920, con prólogo de F. Clemente de Diego; Landelino Lavilla Alsina, El control de la constitucionalidad de las leyes, Madrid, 1977; Carlos López de Haro, La Constitución y las libertades de Aragón y el Justicia Mayor, Madrid, Reus, 1926; Cruz Martínez Esteruelas, «Las funciones del Consejo del Reino», en Revista de Estudios Politicos, núm. 152 (1967), páginas 251-267; Alfonso Pérez Gordo, «El control de la constitucionalidad de las leyes en el Derecho positivo español», en Revista Jur. Cat., núm. 3 (1972), págs. 83-94, también en Estudios de Derecho Procesal, Zaragoza, Pórtico, 1981, págs. 367-380; Luis Sánchez Agesta, La función constitucional del juez. Discurso de ingreso en la Real Academia de Jurisprudencia y Legislación, Madrid, 1967; «El recurso de contrafuero y la protección del orden constitucional», en Revista de Estudios Políticos, núm. 181 (1972), págs. 5-33; José Luis Sanlúcar, «El control de constitucionalidad de la ley y el recurso de contrafuero», en Cuadernos para el Diálogo, diciembre, 1969, extraordinario; Carlos Sanz Cid, «Sobre la etiología del control judicial de la constitucionalidad de las leyes», en Revista del Instituto de Ciencias Sociales, núm. 8 (1966), págs. 39-49; Diego Sevilla Andrés, «La defensa de la Constitución en la Ley Orgánica española», en Revista de Estudios Políticos, núm. 152 (1967), págs. 279-303; Gumersindo Trujillo Fernández, La constitucionalidad de las leyes y su control, en «Dos estudios sobre la constitucionalidad de las leyes», La Laguna, 1970, páginas 5-77; La constitucionalidad de las leyes en el Derecho español. Una interpretación sistemática del recurso de contrafuero, en «Dos estudios sobre la constitucionalidad de las leyes», La Laguna, 1970, págs. 79-132. 


\section{EN LA CONSTITUCION DE $1931^{2}$}

\section{Disposiciones legales}

Artículos 121 a 124 de la Constitución de 9 de diciembre de 1931.

Ley de 14 de junio de 1933, Orgánica del Tribunal de Garantías Constitucionales ${ }^{3}$. Corrección de errores de los artículos 11 y $31^{4}$.

Decreto de 10 de agosto de 1933 sobre elección de vocales del Tribunal de Garantías ${ }^{5}$ y otro de 28 de agosto de 1933 dictado para resolver algunas dudas suscitadas por el anterior ${ }^{6}$.

Ley de 1 de septiembre de 1933 de modificación de los artículos 5 y 27 de la Ley Orgánica del Tribunal de Garantías ?.

Decreto de 20 de octubre de 1933 sobre incompatibilidades de miembros del Tribunal de Garantías ${ }^{8}$.

Decreto de 8 de diciembre de 1933 por el que se aprueba el Reglamento del Tribunal de Garantías 9 .

Decreto de 1 de noviembre de 1934 sobre actuación de los abogados del Estado en recursos de amparo ${ }^{10}$.

Decreto de 6 de abril de 1935 por el que se aprueba un nuevo Reglamento y se deroga el de $1933^{11}$.

Decreto de 7 de junio de 1935 por el que se anula lo dispuesto en el capítulo III, título II del Reglamento anterior. Se trata de los artículos 84 a 94, relativos a los recursos de ilegalidad y exceso o desvío de poder ${ }^{12}$.

Ley de 21 de julio de 1935 de suspensión de elecciones al Tribunal de Garantías Constitucionales en tanto no se celebren elecciones municipales ${ }^{13}$.

Decreto-ley de 13 de abril de 1936 relativo a las competencias del Tribunal de Garantías en el procedimiento de elección de compromisarios para designación del Presidente de la República ${ }^{14}$.

Decretos de 25 y 28 de agosto de 1936 sobre normativa para el funcionamiento del Tribunal ante las dimisiones de los vocales ${ }^{15}$.

Hubo dos proyectos de reforma del Tribunal de Garantías. El primero se incluía en el proyecto de reforma constitucional presentado por el Gobierno Lerroux

${ }^{2}$ Casi toda la documentación relativa al Tribunal de Garantías de la II República española puede encontrarse en el trabajo de Martín Bassols Coma, La jurisprudencia del Tribunal de Garantías Constitucionales, Madrid, Centro de Estudios Constitucionales, 1981. Además del texto de las sentencias, incluye un apartado con los anteproyectos de ley orgánica del Tribunal, debates parlamentarios, texto final, reglamento, etc. Por otra parte, añade un estudio preliminar en el que se abordan los problemas de la creación y funcionamiento del Tribunal, así como el análisis de la doctrina constitucional contenida en sus sentencias.

${ }^{3}$ Gaceta de 30 de junio de 1933.

- Gaceta de 10 de julio de 1933.

5 Gaceta de 13 de agosto de 1933.

- Gaceta de 29 de agosto de 1933.

7 Gaceta de 9 de septiembre de 1933.

${ }^{8}$ Gaceta de 21 de octubre de 1933.

- Gaceta de 9 de diciembre de 1933.

10 Gaceta de 2 de noviembre de 1934.

11 Gaceta de 11 de abril de 1935.

12 Gaceta de 11 de junio de 1935.

${ }^{13}$ Gaceta de 23 de julio de 1935.

14 Gaceta de 14 de abril de 1936.

is Gacetas de 26 y 29 de agosto de 1936. 
el 5 de julio de $1935^{16}$. El segundo es un proyecto de ley de reforma de la Orgánica del Tribunal de Garantías presentado por el Gobierno Azaña el 20 de abril de $1937^{17}$. Ninguno de los dos prosperó.

\section{Nombramiento de vocales, presidentes, constitución} $y$ sede del Tribunal de Garantías

La elección de vocales parlamentarios y del presidente tuvo lugar el 13 de julio de $1933^{18}$. La convocatoria de elecciones de vocales se realizó por los Decretos de 10 y 28 de agosto citados anteriormente. Tuvieron lugar las elecciones de vocales regionales el 3. de septiembre de 1933 y el día 10 las de representantes de Colegios de Abogados y Facultades de Derecho ${ }^{19}$. La convocatoria para la sesión constitutiva, que había de celebrarse el 20 de octubre de 1933, en la Gaceta del 11 de octubre anterior 20 .

Como primer presidente fue elegido don Alvaro de Albornoz, que dimite el 5 de octubre de 1934. El 20 de diciembre del mismo año es elegido don Fernando. Gasset.Lacasaña, que ejerce su cargo hasta el 20 de agosto de 1936; en que dimite tanto él como todos los vocales. La dimisión del presidente es aceptada el 29 de agosto por.la Diputacion Permanente de las: Cortes.

Los Decretos de 25 y 28 de agosto de 1936, ya citados; establecen normas para el funcionamiento del Tribunal ante la situación creada por los dimisionarios.

Hasta febrero de 1934 el Tribunal tesidió en el edificio del antiguo Senado, a la sazón sede de las más dispares comisiones, congresos; reuniones, etc. En febre-ro de 1934 pasa a reunirse en el Palacio de Justicia de: la plaza de las. Salesas. Su sede definitiva estuvo situada en el edificio de la calle de San Bernardo, entrè las de San. Vicente y Espíritu Santo.

En noviembre de 1.936 pasó a Valencia y en octubre de 1937 a Barcelona.

\section{Jurisprudencia}

El artículo 41 de la Ley Orgánica del Tribunal de Garantías establece que las sentencias recaídas en consultas o recursos de inconstitucionalidad y los votos particulares a ellas, si los hubiere, serán publicadas en la Gaceta de Madrid. También era preceptiva la publicación de las resoluciones en cuestiones de competencia legislativa (art. 55.5) o conflictos de atribución (art. 66.3). La Disposicióni Adicional autorizaba al presidente y, por su delegación, al secretario general a ordenar la inserción en la Gaceta de cuantos anuncios, resoluciones o acuerdos considerara convenientes:

Las sentencias del Tribunal de Garantías Constitucionales eran fundadas por expresa imposición de su Ley Orgánica, si bien no tenían que sujetarse a «.... otras formalidades de redacción que las de hacer constar las circunstancias del recựso interpuesto, el nombre y apellidos de los miembros del Tribunal, del ponente y de los defensores y la fecha en que se dicte». Las sentencias respondían a este esquema: tras los nombres de los componentes del Pleno o Sección iba la palabra «Sentencia»

${ }^{16}$ Cfr. Apéndice 4 al núm. 218, de 5 de julio de 1935, del Diario de Sesiones

${ }^{17}$ Cfr. Apéndice 9 al núm. 21, de 20 de abril de 1936, del Diario de Sesiones.

${ }^{18}$ Cfr. Diario de Sesiones de ese día.

${ }^{19}$ Los nombres de los vocales y su adscripción política pueden verse en J. Luis García Ruiz, El recurso de amparo en el Derecho español, págs. 77 y sigs.

» Cfr, en el núm. 43 de la Revista de los Tribunales. la crónica de la sesión constitutiva. 
y la fecha correspondiente. A la identificación del asunto se anteponía la palabra «Visto». El cuerpo de la sentencia aparecía dividido en «antecedentes» y «fundamentos legales». Por último, la fórmula «Por todo lo cual el Tribunal de Garantías Constitucionales falla:». Tras el fallo se incluían las firmas y rúbricas de los componentes del Tribunal.

Los recursos en materia de responsabilidad criminal, sin embargo, no seguían esta forma, ateniéndose a la tradicional de resultandos y considerandos.

La primera sentencia del Tribunal de Garantías es de 8 de junio de 1934 en la cuestión de competencia legislativa promovida por el Gobierno de la República a la Generalidad de Cataluña sobre la Ley de 11 de abril de 1934 de regulación de contratos de cultivo.

A partir de ella, publicada en el núm. 163, aparecieron sentencias en los siguientes números de la Gaceta de Madrid:

1934: $311,313,319,320,335,350,359$.

1935: $24,27,40,54,55,95,99,141,146,149,157,163,187,189,267,268$, $339,345,351,353,354$.

1936: $21,24,68,72,74,80,141,162,185,189$.

1937: 62, 186.

Además de las sentencias publicadas en la Gaceta, existen en el Archivo de la Presidencia del Gobierno los textos de algunas otras, ordinariamente en recursos de amparo, que aparecen reproducidas en el libro de Martín Bassols citado.

El Repertorio de Jurisprudencia de Aranzadi publicaba las sentencias, incluso de amparo, cuando habían aparecido en la Gaceta. Uno de los índices finales reunía las sentencias del año dictadas por el Tribunal. El Boletín Jurídico-Administrativo, apéndice al Diccionario de la Administración Española de Alcubilla, incluía resúmenes de las sentencias del Tribunal en su sección dedicada a Jurisprudencia.

A continuación indicamos una serie de revistas jurídicas que incluían, de forma habitual, una sección dedicada a reseñar las sentencias del Tribunal de Garantías:

- Administración y Progreso, revista de Derecho administrativo y servicios públicos, Madrid, mensual, junio 1932-junio 1936. Director: Rafael Salazar Alonso.

- Revista de Ciencias Iurídicas y Sociales (órgano de la Facultad de Derecho y del Museo-laboratorio jurídico de la Universidad de Madrid), trimestral desde 1932. Director: Adolfo García Posada.

- Revista de Derecbo Público. Publicó comentarios a sentencias en los números. 36, 38, 39, 42, 43-44, 47, 49 y .53. Con excepción de los dos últimos, debidos a Vicente Herrero, los demás a cargo de Tomás Muñoz Molina.

- Revista de los Tribunales. Publicaba crónicas de las reuniones del Tribunal de Garantías.

- Revista de los Tribunales y de Legislación Universal.

- Revista General de Legislación y Jurisprudencia.

- Revista Jurídica de Cataluña.

\section{Bibliografia:}

Alcalá-Zamora y Castillo, Niceto, Significado $\dot{y}$ funciones del Tribunal de Garantías Constitucionales, Madrid, Reus, 1933; también en Ensayos de Derecho Procesal, Civil, Penal y Constitucional, Buenos Aires, 1944. 
- «El Tribunal de Garantías Constitucionales. Antecedentes, naturaleza y objeto de las diferentes funciones que le incumben», en Rev. Trib. y Leg. Univ. 22 (1933); 24 (1933); 25 (1933); 26 (1933) y 28/29 (1933).

Alcalá-Zamora y Torres, Niceto, Los defectos de la Constitución de 1931. Tres años de experiencia constitucional, Madrid, Cívitas, 1981; también, Madrid, Imp. A, Espinosa, 1936.

Almagro Nosete, José, «La "acción popular" ante el Tribunal de Garantías Constitucionales. Valoración crítica», en RDP (UNED), 12 (1982).

Bassols Coma, Martín, La jurisprudencia del Tribunal de Garantias Constitucionales de la II República española, Madrid, CEC, 1981.

BoucsEIN, Wilhelm, Verfassungssicherung an Verfassungsgericbtsbarkeit in der Zweiten Spaniscben Republik (1931-1936), Francfort, Haag \& Herchen, 1977.

CRUZ VILlásón, Pedro, Dos modos de regulación del control constitucional: Cbecoslovaquia (1920-1938) y España (1931-1936), II Congreso de la Asociación Española de Ciencia Política, Sevilla, 1981.

Díaz DE Arcaya y MrRavete, Francisco, El Tribunal de Garantías Constitucionales. Su legislación y doctrina constituyente y constitucional, Madrid, Reus, 1934.

Elola, Javier, «Justicia constitucional», en Rev. Trib., 1 (enero 1931).

Fábregas del Pilar, José María, «Las garantías constitucionales y la reforma de la Constitución», en RGLJ 169 (II) (1932).

- «El Tribunal de Garantías Constitucionales», en RGLJ 163 (IV) (1933), págs. 563-566.

FERNándeZ DE Velasco, Recaredo, «Cuestiones prácticas: el Tribunal de Garantías Constitucionales. La disposición final de la ley», en RDP 19-20 (1933), páginas 234-236.

GaRcía RuIz, José Luis, El recurso de amparo en el Derecbo español, Madrid, Editora Nacional, 1980.

Grrat y Raventós, «El conflicto rabassaire y la cuestión agraria en Cataluña», en $R T, 7$ (1964).

Jrménez DE AsúA, Luis, El Tribunal de Garantias Constitucionales, Conferencia en Granada el 3 de junio de 1933.

- Proceso bistórico de la Constitución de la República española, Madrid, 1932.

Jover, P.: «EI Tribunal de Garantías Constitucionales», en Izq. y la Const., páginas 105-133.

LEGAZ LACAMBRA, Luis, «Las garantías constitucionales del derecho internacional (con especial referencia a la Constitución española)», en $R D P 22$ (1933), páginas 301-313.

Lubac, André, Le Tribunal espagnol de Garanties Constitutionnelles, Montpellier, 1936.

MeIlán GiL, José Luis, «El Tribunal de Garantías Constitucionales de la II República española», en Actas del II Simposio de Historia de la Administración, Madrid, IEA, 1971, págs. 543-599.

MeTALl, Rudolf Aladar, «Verfassungsgerichtsbarkeit in. Spanien», en JUSTIZ (abril 1933).

PÉrez Serrano, Nicolás, La Constitución española (9 diciembre 1931): antecedentes, texto, comentarios, Madrid, 1932.

- «El proyecto del Tribunal de Garantías y el recurso de inconstitucionalidad», en $R D P, 13$ (1933).

Reyes, Rodolfo, La defensa constitucional. Recursos de inconstitucionalidad y amparo, Madrid, Espasa-Calpe, 1934.

RoIg Y Bergadé, J., «Justicia constitucional: Tribunal de Garantíes», en Cónferencies sobre l'Estatut de Catalunya, Barcelona, 1933. 
Ruiz LAPEÑA, Rosa María, «EI recurso de amparo durante la Segunda República española», en REP, 7 (1979).

Tomás VILLARroya, Joaquín, «El recurso de inconstitucionalidad en el Derecho español, 1931-1936», en RICS 11 (1968); págs. 11-52.

\section{EN LA CONSTITUCION DE 1978}

\section{Disposiciones legales ${ }^{21}$}

El Tribunal Constitucional fue establecido por la Constitución de 1978, regulándose en su título IX. La Ley Orgánica $2 / 1979$, de 3 de octubre 2 , desarrolló los preceptos constitucionales relativos al Tribunal. Su Reglamento de Organización y Personal fue aprobado por Acuerdo del Pleno del Tribunal de 15 de enero de 1981. Por sendos Acuerdos de 15 de junio y 14 de julio se aprobaron sus normas de funcionamiento durante el período de vacaciones y las normas para la tramitación de los diversos procesos de inconstitucionalidad ${ }^{23}$.

La Abogacía del Estado ante el Tribunal Constitucional fue creada por Real Decreto $1425 / 1980$, de 11 de julio ${ }^{24}$, siendo su estructura desarrollada por Orden de 2 de abril de $1981^{25}$.

Por último, existe un Acuerdo del Consejo de Ministros de 31 de octubre de 1980 sobre personación y seguimiento de los recursos de inconstitucionalidad en el que se dan instrucciones a los diversos organismos de la Administración en relación con recursos y cuestiones de inconstitucionalidad así como conflictos de competencias $^{26}$.

\section{Nombramiento de Magistrados, Constitución y Sede del Tribunal Constitucional}

En cumplimiento de la disposición transitoria primera de la LOTC fue elevada al Rey la propuesta de designación de los Magistrados elegidos por el Congreso ${ }^{27}$, el Senado ${ }^{28}$ y el Gobierno ${ }^{29}$, que fueron nombrados por sendos Reales Decretos 301 a 310/1980, de 14 de febrero ${ }^{30}$. En aplicación de la disposición transito-

${ }^{21} \mathrm{Cfr}$ :, en este sentido, los comentarios sistemáticos a la Constitución, en los artículos del título IX, como, por ejemplo, los de Oscar Alzaga, Garrido Falla, Sánchez Agesta, etc. La tramitación parlamentaria de la LOTC se encuentra recogida, además de en los correspondientes Boletines Oficiales de las Cortes y Diarios de Sesiones, en Ley Orgánica del Tribunal Constitucional. Trabajos parlamentarios, Madrid, Servicio de Estudios de las Cortes, 1980. El título IX de la Constitución, el texto de la ley, el Reglamento de Organización y Personal y disposiciones complementarias se contienen en el volumen publicado por èl Boletín Oficial del Estado en su colección textos legales: Tribunal Constitucional, Madrid, 1981 .

${ }_{22}$ Boletin Oficial del Estado de 5 de octubre de 1979.

${ }^{23}$ Boletín Oficial del Estado de 2 y 10 de febrero de 1981 y 15 de junio y 19 de julio de 1982.

${ }_{24}$ Boletín Oficial del Estado de 15 de julio y 12 de agosto de 1980.

${ }^{25}$ Boletín Oficial del Estado de 27 de abril de 1981:

${ }^{26}$ Este acuerdo, no publicado en el Boletín Oficial, se recoge en el número monográfico 25 a 28 (1980) de Documentación Jurídica que, con el título de «Materialés para el estudio y aplicación de la Constitución de 1978», publicó el Ministerio de Justicia.

${ }_{27}$ Francisco Rubio Llorente, Aurelio Menéndez Menéndez, Manuel Díez de Velasco Vallejo y Francisco Tomás y Valiente.

${ }_{23}$ Manuel García-Pelayo y Alonso, Gloria Begué Cantón, Luis Díez-Picazo y Ponce de León y Angel Latorre Segura.

\footnotetext{
${ }^{29}$ Jerónimo Arozamena Sierra y Rafael Gómez-Ferrer Morant.
}

30 Boletin Oficial del Estado de 22 de febrero de 1980. 
ria 1.2, el Tribunal se constituyó dentro de los quince días siguientes al término del período legislativo en que se realizaron estos primeros nombramientos. Quedó pendiente la propuesta correspondiente al Consejo General del Poder Judicial, que no se constituyó hasta el 23 de octubre de 1980.

El Tribunal Constitucional quedó constituido el 12 de julio de 1980, en sesión pública y solemne, presidida por S. M. el Rey ${ }^{31}$. Por Acuerdo del Pleno del Tribunal Constitucional de 14 de julio de 1980 fue fijada la fecha del 15 del mismo mes y año para el comienzo del ejercicio de sus competencias ${ }^{32}$.

Constituido el Consejo General del Poder Judicial, propuso los candidatos que le corresponden ${ }^{33}$, siendo nombrados por Reales Decretos 2514 y $2515 / 1980$, de 7 de noviembre ${ }^{34}$. Posteriormente dimitió uno de los miembros correspondientes al Congreso ${ }^{35}$, y éste propuso otro candidato ${ }^{36}$, siendo nombrado por Real Decreto $52 / 1981$, de 9 de enero ${ }^{37}$.

Elegidos por el Pleno del Tribunal Constitucional, conforme a lo preceptuado en los artículos 160 de la Constitución y 9 de la LOTC, como Presidente y Vicepresidente don Manuel García-Pelayo y Alonso y don Jerónimo Arozamena Sierra, fueron nombrados por Reales Decretos 1322 y 1323/1980, de 4 de julio ${ }^{38}$.

Desde los primetos nombramientos, los miembros del Tribunal Constitucional se constituyeron en Colegio de Magistrados con el fin de realizar los trabajos preparatorios para la puesta en funcionamiento del Tribunal, celebrando sus reuniones en la sede del Centro de Estudios Constitucionales, hasta que pasó a ocupar, provisionalmente, el edificio del paseo de la Habana, 140-142. El Gobierno remitió al Congreso un Proyecto de Ley de concesión de un suplemento de crédito de 1.090 millones de pesetas para adquisición por el Estado de un inmueble que se adscribiría a sede del Tribunal Constitucional ${ }^{39}$, que, tras su tramitación parlamentaria, se convirtió en la Ley 9/1981, de 11 de mayo ${ }^{40}$. El Tribunal se trasladó a esta sede definitiva de la calle de Domenico Scarlatti, 6, el 16 de septiembre de 1981. Por resolución de la Presidencia del Tribunal Constitucional del mismo día se hizo público el traslado y se fijaron fecha y días en que permanecería abierto el Registro General del Tribunal ${ }^{41}$.

\section{Jurisprudencia 42}

La Constitución establece en su artículo 164 que las sentencias del Tribunal se publicarán en el Boletín Oficial del Estado, y la LOTC, en el artículo 86.2,

${ }^{31}$ La Presidencia del Gobierno editó en 1980 el folleto El Tribunal Constitucional incluyendo reseña del acto de constitución y los discursos pronunciados entonces por el magistrado Gómez-Ferrer, por el presidente del Tribunal y por Su Majestad el Rey. También se incluía el texto de la LOTC.

${ }_{32}$ Boletín Oficial del Estado de 14 de julio de 1980.

33 Angel Escudero del Corral y Plácido Fernández Viagas.

34 Boletín Oficial del Estado de 19 de noviembre de 1980.

${ }^{35}$ Aurelio Menéndez Menéndez.

${ }^{36}$ Antonio Truyol y Serra.

${ }_{37}$ Boletín Oficial del Estado de 14 de enero de 1981.

${ }^{38}$ Boletín Oficial del Estado de 7 de julio de 1980.

${ }^{39}$ Boletín Oficial de las Cortes, Congreso, Serie A, núm. 160.

* Boletín Oficial del Estado de 15 de mayo de 1981.

41 Boletín Oficial del Estado de 26 de septiembre de 1981.

2 El artículo 99.2 de la LOTC establece que "corresponde igualmente a la Secretaría General la recopilación, clasificación y publicación de la doctrina constitucional del Tribunal». Aunque hasta la fecha no ha habido ninguna publicación en tal sentido, próximamente se publicarán en forma de repertorio las sentencias y autos por los servicios propios del Tribunal. 
especifica que deberán ser publicadas dentro de los treinta días siguientes a la fecha del fallo. Por otra parte, no tiene carácter oficial más que el texto publicado en el Boletin Oficial ${ }^{43}$.

En la estructura formal de las sentencias se aprecian tres partes netamente diferenciadas: el encabezamiento, el cuerpo propiamente dicho y el fallo. El encabezamiento anuncia la Sala que ha tomado la decisión o el Pleno, en su caso, con los nombres de sus componentes, que es el sujeto del comienzo de la fórmula votiva «ha pronunciado en nombre del Rey la siguiente sentencia». Tras la identificación del asunto se añade: «siendo ponente el Magistrado don ...». A partir de la sentencia 6/1982, de 22 de febrero, esta última expresión de la fórmula se completó con la frase: «quien expresa el parecer del Tribunal». El cuerpo de la sentencia se compone de una primera parte de antecedentes en los que se refieren el origen del proceso, las alegaciones de las partes, las actuaciones seguidas, etc., a la que sigue una segunda de fundamentos jurídicos en la que se establece la justificación constitucional del fallo. Los fundamentos están numerados.

Por último, tras la palabra FALLo, continúa la fórmula: «En atención a todo lo expuesto, el Tribunal Constitucional, por la autoridad que le confiere la Constitución de la Nación española, ha decidido...».

La primera sentencia es la de la Sala Segunda, recaída en el Recurso de Amparo número $65 / 80$ y lleva fecha de 26 de enero de 1981. Las sentencias dictadas a lo largo de 1981 se identifican por la fecha y el número de registro del asunto de que traten. A partir de 1982, sin embargo, se numeran siguiendo el orden de fecha en que se dictó el fallo, con independencia del tipo de asunto y de si son de Pleno o de Sala.

E1 Boletín Oficial del Estado publica las sentencias en forma de suplementos al número del día correspondiente, sin que hasta ahora se haya planteado la modificación del Reglamento del Boletín para la creación de una nueva sección que las recoja. Hasta la fecha se han publicado suplementos de sentencias del Tribunal Constitucional en los siguientes números del Boletin: 47, 89, 99, 121, 143, 161, $171,172,193,277,285,305$, en 1981, y 12 (contiene sentencias de 1981), 49, $69,95,118,137,153,169,185,197$ y 276 de 1982 .

La colección Disposiciones Generales incluye las sentencias del Tribunal Cons: titucional recaídas en recursos y cuestiones de inconstitucionalidad y conflictos de competencia. Todo ello por lo que se refiere a colecciones oficiales:

Entre los repertorios privados, el cronológico de legislación de Aranzadi hace lo mismo con las sentencias que afectan a preceptos legales, y el periódico La Ley y sus acumulaciones trimestrales incluye todas las sentencias, incluso las recaídas en recursos de amparo.

Exite, además, confeccionado y editado por el Servicio de Estudios de las

${ }^{43}$ Es claro que al ser la Constitución una ley inmediatamente aplicable existe una jurisprudencia constitucional de los órganos jurisdiccionales ordinarios a la que no nos referimos aquí y que puede encontrarse en los repertorios jurisprudenciales de carácter general (Colección Legislativa Aranzadi, La Ley, etc.).

Resúmenes o análisis específicos de la jurisprudencia del Tribunal Supremo pueden encontrarse en: Enrique Linde Paniagua, «Sentencias y autos del Tribunal Supremo y Resoluciones de la Dirección General de los Registros que se citan, estudian o aplican preceptos constitucionales», en Revista de Derecbo Político, Universidad Nacional de Educación a Distancia, 6 (1980), 7 (1980), 8 (1981), 9 (1981), 10 (1981) y 13 (1982); Luis Prieto Sanchís, «Dos años de jurisprudencia del Tribunal Supremo sobre cuestiones constitucionales», en Revista Española de Derecho Constitucional I, 1 (1981), pp. 207-234; I, 2 (1981), págs. 215-248, y I, 3 (1981), págs. 191-232; José María Rodríguez Oliver, «La Constitución española en la jurisprudencia del Tribunal Supremo", en Revista de la Facultad de Derecho de la Universidad Complutense, núm. 58 (1980), págs. 101-142. Así como en el ya citado «Materiales para el estudio y aplicación de la Constitución de 1978». 
Cortes Generales, un Boletin de Jurisprudencia Constitucional que reproduce las sentencias y autos del Tribunal Constitucional. Con periodicidad mensual, comenzó a publicarse en mayo de 1981. El número 8, correspondiente a diciembre, incluye un índice anual ${ }^{44}$. Además ha comenzado a editar una serie anual: Jurisprudencia constitucional sistematizada, dedicada a insertar toda la jurisprudencia emitida por el Tribunal Constitucional, así como los votos particulares.

La primera parte está formada por una serie de índices que remiten a la sentencia y al número del fundamento jurídico de que se trate. Los índices son: 1) Constitucional (según los artículos de la Constitución); 2) Estatutos de autonomía (según los artículos de cada Estatuto); 3) Materias (alfabético por voces y subvoces); 4) Ley Orgánica del Tribunal Constitucional (según sus artículos); 5) Leyes y disposiciones generales (por artículos dentro de cada ley o disposición mencionada); 6) Convenios internacionales y sentencias de tribunales internacionales; 7) Preceptos declarados nulos o derogados por el Tribunal Constitucional.

La segunda parte reproduce los cuatro primeros índices, si bien, además de la referencia respectiva, añade el párrafo o párrafos de ésta en que se contiene la doctrina de que se trate.

El ya citado Materiales para el estudio y aplicación de la Constitución española de 1978 incluye las sentencias del Tribunal Constitucional, a las que se añaden índices: constitucional, de materias, etc. Desconocemos si en números de Documentación Jurídica posteriores a este monográfico se continuarán incluyendo las sentencias del Tribunal Constitucional.

Diversas revistas especializadas han iniciado secciones fijas que recogen, en forma abreviada ordinariamente, las sentencias del Tribunal Constitucional. La continuidad de tales secciones, así como su permanencia, es algo que sólo el paso del tiempo aclarará. Citamos a continuación algunas de ellas.

Documentación Laboral. A partir de su número 3 (1982) inicia una sección de «Doctrina del Tribunal Constitucional» en la que incluye reseña de las sentencias, recogiendo, básicamente, las que afectan al Derecho laboral y de la Seguridad Social. La revista está editada por la Asociación de Cajas de Ahorro para las Relaciones Laborales.

Presupuesto y Gasto Público. Incluye en cada número una «Crónica constitucional» a cargo de Fernando Díez Moreno, que frecuentemente comenta la jurisprudencia del Tribunal Constitucional, tanto reseñando sentencias concretas -número 8 (1980), por ejemplo - como doctrina del Tribunal Constitucional en forma global - conflictos de competencias en materia de Cajas de Ahorro, número 9 (1981).

- Revista de Derecbo Político (UNED). El Departamento de Derecho Administrativo de la UNED es el responsable de la sección de Jurisprudencia Constitucional iniciado en el núm. 12 (1981-82) de esta revista. La coordinación corresponde a Tomás-Ramón Fernández Rodríguez. Tras una pequeña reseña cronológica de las sentencias de 1981 con sus correspondientes índices constitucional, de materias, etcétera, incluye aspectos concretos: derecho de huelga, libertad de enseñanza, etc., en que trata con más amplitud las sentencias habidas.

Revista de Derecbo Público. A veces publica una sección de «Jurisprudencia del Tribunal Constitucional», con comentarios o textos de sentencias. Con carácter

* El Boletín de Jurisprudencia Constitucional contiene, además, las sentencias del Tribunal Supremo que aplican la Constitución, jurisprudencia del Tribunal Europeo de Derechos Humanos y una sección de jurisprudencia constitucional extranjera que reseña decisiones del Tribunal Constitucional Federal alemán, el Consejo de la Revolución portugués, la Corte Constitucional italiana, el Tribunal Constitucional austríaco, el Tribunal Federal suizo, el Consejo Constitucional francés, etc. 
permanente, mantiene una sección llamada «Jurisprudencia penal del Tribunal Supremo y del Tribunal Constitucional», a cargo de Enrique Peñaranda Ramos.

Revista de la Facultad de Derecho de la Universidad Complutense. Comenzó una "Crónica de jurisprudencia constitucional», en el núm. 62 (1981), a cargo de Luis Aguiar de Luque.

Revista Española de Derecbo Constitucional. A partir del núm. 3 (1981) incluye una crónica informativa del Tribunal Constitucional con la que «... pretende informar a sus lectores de todas las sentencias que el Tribunal Constitucional vaya dictando...». La primera, a cargo de Luis Aguiar de Luque, lleva por título: «Relación de las sentencias del Tribunal Constitucional durante el primer semestre de $1981 »$.

Revista General de Derecho. Mantiene una sección de jurisprudencia constitucional a cargo de José María Martínez Val.

Revista Jurídica de Cataluña. A partir del número 2 (1982) incluye una sección de «Jurisprudencia del Tribunal Constitucional». Da un resumen de cada una de las sentencias. La parte de recursos de amparo está a cargo de Alfonso de Alfonso Bozzo.

Revista Vasca de Administración Pública. A partir del número 2 (1982) inaugura una sección de «Jurisprudencia del Tribunal Constitucional», en la que incluye los textos de las sentencias directamente referidos a la Comunidad Autónoma Vasca, así como información de los asuntos pendientes ante el Tribunal.

En este orden de cosas, reseñamos a continuación algunos comentarios a sentencias determinadas aparecidos en revistas especializadas. La prensa diaria y revistas de carácter general han publicado con frecuencia comentarios de especialistas al hilo de la actualidad de algunos asuntos tratados en las sentencias que no incluimos en esta bibliografía.

\section{Comentarios a sentencias ${ }^{45}$}

Albacar, José Luis, «El principio de libre apreciación de la prueba en la doctrina

${ }^{45}$ Somos partidarios de normalizar las abreviaturas de las revistas según las recomendaciones de los organismos. internacionales correspondientes. Sin embargo, en este caso, debido a que casi todas las citas son de revistas españolas, hemos utilizado las abreviaturas usuales entre nosotros. Son: $A D H$, Anuario de Derechos Humanos; $A J$; Actualidad Jurídica; $A P$, Administración Pública; $B C E$, Boletín del Círculo de Empresarios; BICAM, Boletín del Ilustre Colegio de Abogados de Madrid; BIMJ, Boletín de Información del Ministerio de Justicia; $D A$, Documentación Administrativa; EGZ, Europaische Grundrechte Zeitschrift; $H P E$, Hacienda Pública Española; JORG, Jahrbuch des. Oeffentlichen Recht der Gegenwart; JSSS, Jurisprudencia de Seguridad Social y. Sanidad; RAP, Revista de Administración Pública; RDDP (UNED), Revista del Departamento de Derecho Político de la UNED; RDP, Revista de Derecho Público; $R D P$ (UNED), Revista de Derecho Político; RDPI, Revista de Derecho Procesal Iberoamericana; REDA, Revista Eśpañola de Derecho Administrativo; $R E D C$, Revista Española de Derecho Constitucional; REDT; Revista Española de Derecho del Trabajo; REP, Revista de Estudios Políticos; REVL, Revista. de Estudios de la Vida Local; RFDUC, Revista de la Facultad de Derecho de la Universidad Complutense; RGLJ, Revista General de Legislación y Jurisprudencia; RICA, Revista. Internacional de Ciencias Administrativas; RICS, Revista del Instituto de Ciencias Sociales; $R J C$, Revista Jurídica de Cataluña; RPC, Revista de Política Comparada; RPS, Revista de Política Social; $R T$, Revista de Trabajo; RVAP, Revista Vasca de Administración Pública; US, Universidad y Sociedad. Por lo que se refiere a los libros colectivos citados son: La Constitución española y las fuentes del Derecbo, Jornadas de estudio organizadas por la Dirección General de lo Contencioso del Estado, Madrid, 1979; Giuseppe de Ver-. gottini, Una costituzione democratica per la Spagna, Milán, 1978; Lecturas sobre la Constitución española, Madrid, UNED, 1978; Libro bomenaje al profesor Juän Gälván Escutia, Valencia, 1980; El Tribunal Constitucional, Jornadas de estudio organizadas por la Dirección General de lo Contencioso del Estado, Madrid, 1981. 
del Tribunal Constitucional», en La Ley, núm. 292, noviembre 1981. (Comentario a la STS de 28 de julio de 1981.)

Alfonso Bozzo, Alfonso de, «Derecho de huelga y conflictos colectivos de trabajo (Comentario a la STC de 8 abril 1981)», en RJC, 1 (1982), págs. 185-192. págs. 123-168.

Amorós DoRDA, F. Javier, «Inconstitucionalidad del presupuesto. (Comentario de - la STC de 20 julio 1981 sobre inconstitucionalidad de determinados preceptos de la Ley de Presupuestos para 1981)», en RDP, 87 (1982), págs. 495-520.

Aragón ReYes, Manuel, «La sentencia del 'Tribunal Constitucional sobre leyes relativas al régimen local, anteriores a la Constitución», en REDC, 1 (1981), págs. 185-205.

Balza Agurlera, Javier y otros, «Las potestades normativas de la Comunidad Autónoma del País Vasco», en RVAP, 2 (1982), págs. 171-200.

Bercovitz Rodríguez-Cano, Rodolfo, «La ejecución de las sentencias eclesiásticas de separación matrimonial por la jurisdicción civil después de la Constitución. Comentario a la STC de 26 de enero de 1981», en REDC (I), 3 (1981), págs. 123-168.

Borrajo DACRUZ, Efrén, «El derecho de huelga de los funcionarios públicos en la STC de 8 de abril de 1981», en REDC (1981), págs. 131-158.

C.E.O.E., «Notas acerca de la Sentencia del Tribunal Constitucional sobre el derecho de huelga», en Informes y Estudios, 6 (mayo 1981).

Coberos Mendoza, E., «E1 derecho a asociarse en partidos políticos y su protección por el Tribunal Constitucional», en RVAP, 1 (1981), págs. 217-226.

Coca VITA, Eduardo, «La Sentencia del Tribunal Constitucional de 28 de julio de 1981 y su alcance para otras leyes de transferencias parciales de competencias provinciales», en REDA, 31 (1981), págs. 709-717.

CoNs García, Javier, «Sobre derechos fundamentales y libertades públicas. Delimitación del derecho a la huelga», en La Ley, núm. 170, mayo 1981. (Comentario en torno a la STC de 8 de abril de 1981.)

Dif́guez, Gonzalo, «Los excursos del Tribunal Constitucional en materia de lockout», en La Ley, núm. 333, enero 1982. (Sobre los fundamentos jurídicos 22 y 17 de la Sentencia de 8 de abril de 1981.)

Díez Moreno, Fernando, «Comentarios de jurisprudencia constitucional. STC de 28 de julio de 1981 por la que se declara inconstitucional la ley del Parlamento Catalán de 17 de diciembre de 1980 , sobre transferencia urgente y plena a la Generalidad de las Diputaciones catalanas», en $A J$ VII (1981), páginas 61-71.

- «Efectos civiles en relación con los hijos, de las sentencias eclesiásticas de separación y nulidad matrimonial», en $A J$ IV (1981), págs. 17-23. (STC de 26 de enero de 1981.)

- «Jurisprudencia constitucional en materias financieras», en HPE, 70 (1981), págs. 211-220.

- «La inconstitucionalidad de la Ley de Derechos Pasivos en materia de jubilación por incapacidad física», en HPE, 71 (1981), págs. 179-196.

- «El significado de la "competencia legislativa básica" del Estado en la jurisprudencia constitucional», en $A J, 8$ (1981), págs. 63-72.

La doctrina del Tribunal Constitucional en materia de buelga y conflictos colectivos (Sentencia de 8 de abril de 1981), Madrid, Instituto de Estudios Sociales, 1981; 178 págs.

García de Enterría y Martínez Carande, Eduardo, «La incidencia de la Constitución sobre la potestad sancionadora de la administración: dos importantes sentencias del Tribunal Constitucional», en REDA, 29 (1980), págs. 359-368. (Sentencias 30-I-81 y 8-VI-81.) 
García Fernáñdez, Javier, «El concepto de autonomía municipal según el Tribunal Constitucional», en RFDUC, 61 (1980), págs. 185-222.

GonzÁlez García, Eusebio, «Comentario sobre la sentencia de inconstitucionalidad de 4 artículos de la Ley de Presupuestos del Estado para 1981», en HPE, 72 (1981), págs. 188-196. Además, DíEz Moreno, Fernando, «Análisis de la referida sentencia», págs. 197-206, y Rodrigo FERnándeZ, Jesús, «Comentario de un aspecto de dicha sentencia», págs. 206-214.

JIMÉNEZ CAMPo, Javier, «La intervención estatal del pluralismo. (Notas a una sentencia del Tribunal Constitucional)», en REDC (I), 1 (1981), págs. 161-184. (Sentencia de 2 de febrero de 1981.)

Jiménez dE PARGA, Manuel, «El contenido esencial de los derechos y libertades. Asunción por el legislador constitucional de una norma preconstitucional» (comentario a la STC de 8 de abril de 1981), en $A J$ IV (1981), págs. 29-34.

JimÉNEZ LuNA, Pedro-Alvaro, «Derogación expresa e inconstitucional sobrevenida: importante sentencia del Tribunal Constitucional», en La Ley, núm. 126, marzo 1981.

JuRISTo SÁnchEZ, Rafael, «Comentario a la STC de 3 de febrero de 1981 sobre la Ley Orgánica del Estatuto de Centros Escolares», en RDP, 87 (1982), páginas $477-493$.

LÓPEZ GANDía, Juan, «Jubilación y política de empleo (STC de 2 de julio de 1981)», en JSSS (III), 13 (1981).

López Menudo, Francisco, «La irretroactividad de las leyes en la Constitución de 1978» (comentario a la STC 20 julio 1981 sobre la Disp. ad. 5. a de la Ley de Presupuestos Generales del Estado para 1981), en $R E D A, 31$ (1981), páginas 718-728.

Lorente Hurtado, Fernando, «Notas sobre jurisprudencia constitucional. (La eficacia normativa de la Constitución y el significado de las leyes orgánicas en las primeras sentencias del Tribunal Constitucional», en La Ley, núm. 180, junio 1981.

Lorenzo García, Rafael de, «Jurisprudencia social. La STC de 8 abril 1981 sobre el RDL de relaciones de trabajo», en US, 2 (1982).

Martín MATEO, Ramón, «Autonomía y régimen local preconstitucional (STC de 2 febrero 1981)», en REDA, 29 (1981), págs. 369-377.

MuÑoz MACHAdo, Santiago, «La jurisprudencia del Tribunal Constitucional sobre las potestades legislativas de las CC. AA.», en REDA, 30 (1981), págs. 551-562.

Parejo Alfonso, Luciano, «El contenido esencial de los derechos fundamentales en la jurisprudencia constitucional, a propósito de la STC de 8 abril 1981», en REDC (I), 3 (1981) págs. 169-190.

- Garantía institucional y autonomias locales, Madrid, IEAL, 1981; 167 págs.

Pibernat, Xavier, «Reserva de ley orgánica y derecho a la educación. Los motivos 4. ${ }^{\circ}$ y $5^{\circ}$ de la Sent. de 13 febrero $1981 »$, en RJC, 2 (1982), págs. 221227.

Prieto Sanchís, L., «Tres recursos de inconstitucionalidad», en RFDUC, 59 (1980), págs. 201-242.

Rodríguez Moro, Nemesio, «La autonomía de los entes territoriales locales en la Constitución española de 27 de diciembre de 1978. (Comentario a la Sentencia de 2 de febrero de 1981)», en REVL, 213 (1982), págs. 134-168.

RODRÍGUEZ OLLER, José María: «La inconstitucionalidad sobrevenida: el voto particular a la STC de 2 febrero 1981», en La Ley, núm. 170, mayo 1981.

Rojo TORRECILla, Eduardo, «El Tribunal Constitucional ante el derecho de huelga», en RPC, 5 (1981), págs. 149-176.

SÁNCHEZ Ageśta, Luis, «Las primeras sentencias del Tribunal Constitucional», en

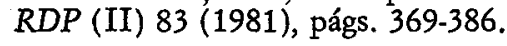


«STC de 8 abril 1981 sobre la constitucionalidad de la actual regulación de la huelga y del cierre patronal», en BCE, 12 (1981), págs. 37-54.

SÁnCHEZ Morón, Miguel, «Las Comunidades Autónomas y las provincias. (Comentario de la STC sobre la Ley de Transferencia de las Diputaciones Catalanas a la Generalidad)», en REDA, 32 (1982), págs. 867-878.

Tagliavia López, Donato, «La inconstitucionalidad de la jubilación forzosa. (Comentario jurisprudencial de la STC de 2 julio 1981)», en REDT, 8 (1981), págs. 513-519.

\section{BIBLIOGRAFIA}

A continuación incluimos una bibliografía sobre algunos aspectos de la jurisdicción constitucional en España tras la Constitución de 1978. Distribuida en grandes grupos y dentro de cada uno alfabéticamente por autores, esperamos pueda tener alguna utilidad.

\section{Aspectos generales}

Aguiló Lucía, Luis, «La presencia de las nacionalidades y regiones en el Tribunal Constitucional», en Trib. Const., I, págs. 349-367.

Almagro Nosete, José, Justicia constitucional. (Comentarios a la Ley Orgánica del Tribunal Constitucional), Madrid, Dykinson, 1980.

- «Poder judicial y Tribunal de Garantías en la nueva Constitución», en Lect. Const. Esp., I, págs. 283-344.

- «Tres breves notas sobre Derecho procesal constitucional», en RDPI, 3/4 (1979), págs. 681-692. También, RDDP (UNED), 5 (1980), págs. 77-82.

Arozamena SiERra, Jerónimo, «Valor de la jurisprudencia constitucional», en Const. Esp. y Fuent. Der., I, págs. 253-279.

Bocanegra Sierra, Raúl, El valor de las sentencias del Tribunal Constitucional. Prólogo por Rafael Gómez-Ferrer, Madrid, IEAL, 1982.

Carretero PÉrez, Adolfo, «El Tribunal Constitucional, el Tribunal Supremo y los Tribunales Superiores de las Comunidades Autónomas», en Trib. Const., I, págs. 603-627.

CaScajo CaSTRo, José Luis, «Aproximación al tema de las funciones del Tribunal Constitucional», en Trib. Cons., I, págs. 629-642.

Domínguez Martín, Salvador, «Análisis crítico sobre la juridicidad del Tribunal Constitucional español», en Trib. Cons., I, págs. 733-795.

- «El Tribunal Constitucional español y su entorno europeo», en Trib. Cons. I, págs. 797-857.

ELIZALDE Y AYMERICH, Pedro de, «El Tribunal Constitucional y la jurisprudencia», en Trib. Cons., I, págs. 859-899.

FAIREN GuILlÉN, Víctor, «Algunos problemas procesales que plantea la Ley Orgánica del Tribunal Constitucional español», en Trib. Cons., II, págs. 981-1029.

FALLER, Hans-Joachim, «Das spanische Verfassungsgericht», en JORG, 29 (1980), págs. 279-292.

- «Verfassungsgerichtsbarkeit in Spanien», en EGZ, 9/10 (1979).

FERnÁNDEZ-CARNICERo GoNZÁlEZ, C. J., «La interpretación de la norma constitucional», en Const. Esp. y Fuent. Der., II, págs. 783-799.

Fix Zamudio, Héctor, «Función constitucional del organismo judicial en México y en España», en ${ }^{\prime} R E P, 10$ (1979), págs. 25-57, y 11 (1979), págs. 37-62.

Galeoti, S., y Rosse, B., «El Tribunal Constitucional en la nueva Constitución 
española. Medios de impugnación y legitimados para actuar»», en $R E P, 7$ (1979), págs. 119-143.

García de Enterría $\mathrm{x}$ Martínez-Cárande, Eduardo, «La posición jurídica del Tribunal Constitucional en el sistema español: posibilidades y perspectivas», en Trib. Cons., I, págs. 21-129. También, REDC (I), 2 (1981).

García-Pelayo y Alonso, Manuel, «El status del Tribunal Constitucional», en REDC (I), 1 (1981), págs. 11-34.

Garrorena Morales, Angel, «La sentencia constitucional», en RDP, 11 (1981), págs. 7-28.

Gerpe Landin, Manuel, «El Tribunal Constitucional (Presentación)», en RJC, 1 (1982), págs. $175-184$.

Gómez DE LAS RocEs, Hipólito, «E1 Tribunal Constitucional y las Comunidades Autónomas», en Trib. Cons., I, págs. 297-346.

González Delerto, N., "Justicia constitucional», en BICAM (enero-marzo 1979).

— «La Ley Orgánica del Tribunal Constitucional», en BICAM (julio-septiembre 1979).

- Tribunales Constitucionales, organización y funcionamiento, Madrid, Tecnos, 1980; 158 págs.

GonZÁlez GaRcía, Eusebio, «Aportaciones que cabe esperar del Tribunal Constitucional en materia tributaria a la vista del Derecho comparado», en Trib. Cons., II, págs. 1171-1217.

GonzÁlez PÉREZ, Jesús, Derecbo procesal constitucional, Madrid, Cívitas, 1980.

Gordillo García, M., «La jurisprudencia en la Constitución», en Const. Esp. y Fuent. Der., II, págs. 1177-1190.

Guaita Martorell, Aurelio, «Los actos administrativos del Tribunal Constitucional», en REDA, 29 (1981), págs. 239-252. También, Trib. Cons., II, páginas 1287-1308.

- «Régimen de los derechos constitucionales», en RDP (UNED), 13 (1982), págs. 75-93.

Herrero de Miñón, Miguel, «En torno a la aplicación de la Constitución», en Const. Esp. y Fuent. Der., II, págs. 1215-1251.

«Informe: El Tribunal Constitucional», en Procuradores, 3 (1982), págs. 4-18.

Jiménez de PARga, Manuel, «Lo que se espera del Tribunal Constitucional», en $A J, 3$ (1981), págs. 35-43.

Juan Martín, Angel de, «Comentarios en torno a la jurisdicción constitucional», en Trib. Cons., II, págs. 1329-1356.

Linde Paniagua, Enrique, «Las leyes orgánicas parciales en la doctrina del Tribunal Constitucional (un ejemplo práctico en el anteproyecto de Ley de Contrabandos)», en RAP, 94 (1981), págs. 339-344.

LÓPEZ Garrido, Diego, «Un año del Tribunal Constitucional: la fijación jurisprudencial de su función y competencias. El concepto de inconstitucionalidad sobrevenida», en RDP (UNED), 13 (1982), págs. 199-209.

LÓPEZ GuERrA, Luis, «El Tribunal Constitucional y el principio "Stare decisis"», en Trib. Cons., II, págs. 1433-1455.

Lucas Murillo de la Cueva, Pablo, «El Tribunal Constitucional y la garantía de la Constitución», en US, 1 (1981), págs. 11-28.

LuCas VERDú, Pablo, «Política y justicia constitucionales. Consideraciones sobre la naturaleza y funciones del Tribunal Constitucional», en Trib. Cons., II, páginas 1483-1550.

Manzari, Giuseppe, «La abogacía del Estado y el Tribunal Constitucional», en Trib. Cons., I, págs. 253-274.

Martín Delgado, José María, «El control constitucional del principio de capacidad económica», en Trib. Cons., II, págs.' 1571-1618. 
Martín Mateo, Ramón, «La garantía constitucional de las autonomías locales», en Trib. Cons., II, págs. 1619-1639.

MARTÍNEz EMPERADOR, R., Los órganos jurisdiccionales y la constitución en «Derecbo del Trabajo y de la S. Social en la Constitución», Madrid, CEC, 1980. También en RPS, 121 (1979).

Martínez Sospedra, Manuel, «EI Tribunal Constitucional como órgano político»; en Trib. Const., II, págs. 1785-1821.

Montoro Puerto, Miguel, «Funciones del Ministerio Fiscal ante el Tribunal Constitucional», en $R A P, 91$ (1980), págs. 171-192.

- «EI Ministerio Fiscal ante el Tribunal Constitucional», en Trib. Cons., III, págs. 1897-1934.

Ortega Díaz-Ambrona, Juan Antonio, «La primacía de la Constitución en el ordenamiento jurídico», en Trib. Cons., III, págs. 2681-2696.

OtTo PARDo, Ignacio de, «La posición del Tribunal Constitucional a partir de la doctrina de la interpretación constitucional», en Trib. Cons., III, págs. 1935. 1951.

PABÓN DE AcuÑa, José María, «Las funciones del abogado del Estado en el proceso constitucional», en Trib. Cons., III, págs. 1953-1994.

Peces-Barba Martínez, Gregorio, «EI Tribunal Constitucional», en Trib. Cons., III, págs. 2033-2093.

Pera Verdaguer, Francisco, «Fuentes del Derecho, jurisprudencia y constitucionalidad», en Const. Esp. y Fuen. Der., III, págs. 1607-1628.

PÉREz GoRdo, Alfonso, «EI Tribunal Constitucional como órgano jurisdiccional», en Estudios de Derecbo procesal, Zaragoza, 1981, págs. 381-404.

PrIETo SANCHís, Luis, «La jurisprudencia constitucional y el problema de las sanciones administrativas en el Estado de Derecho», en $R E D C$ (11), 4 (1982), págs. 99-121.

Rodríguez OrIver, José María, «Los ámbitos exentos del control del Tribunal Constitucional español», en Trib. Cons., III, págs. 2269-2360.

Rubio Llorente, Francisco, Del Tribunal de Garantías al Tribunal Constitucional. Lección inaugural del curso 1980-81 en el Centro Asociado de Extremadura de la UNED en Mérida, Mérida, 1981; 18 págs.

- «Sobre la relación entre Tribunal Constitucional y poder judicial en el ejercicio de la jurisdicción constitucional», en REDC (II), 4 (1982), págs. 35-68.

Rubio Llorente, Francisco, y Aragón Reyes, Manuel, «La jurisdicción constitucional», en Const. Esp. de 1978, 1980, págs. 797-852.

RuIZ DE LA PEÑA, R., «E1 Tribunal Constitucional», en Est. Const. Esp., páginas 379-401. También en Andalán, 247 (7-13 diciembre 1979).

SANDULlI, A., «Justicia administrativa y Constitución», en REP, 7 (1979).

Serna Masía, José, «La legitimación de la administración del Estado en el proceso constitucional», en Trib. Cons., III, págs. 2497-2517.

Tejerizo López, José Manuel, «Competencias del Tribunal Constitucional en materia tributaria», en Trib. Cons., III, págs. 2633-2659.

Tomás VIllarosa, Joaquín, «E1 Tribunal Constitucional en el anteproyecto de Constitución», en Est. Proy. Const., 1978, págs. 199-216.

VEgA, Pedro de, «Jurisdicción constitucional y crisis de la Constitución», en REP, 7 (1979), págs. 93-118.

\section{Control de constitucionalidad}

Angulo Rodríguez, Edmundo, «El control de constitucionalidad y legislación delegada», en Trib. Cons., I, págs. 487-554. 
Aragón Reyes, Manuel, «El control de constitucionalidad en la Constitución española de $1978 »$, en REP, 7 (1979), págs. 171-195.

- «Dos cuestiones interesantes en nuestra jurisdicción constitucional: control de las leyes anteriores y de la jurisprudencia», en Trib. Cons., I, págs. 555-574.

Arozamena Sierra, Jerónimo, «El recurso de inconstitucionalidad», en Trib. Cons., I, págs. 131-177.

BotTaRi, C., «Il controllo della costituzionalità», en Cost. Democ. Spag., págs. $245-$ 254.

Corcuera Atienza, J., «Autonomía y recurso de inconstitucionalidad: legitimación de los órganos de las CC. AA. para interponer recurso de inconstitucionalidad», en RVAP, 1 (1981), págs. 193-216.

Cruz Villatón, Pedro, «El control previo de constitucionalidad», en $R D P, 82$ (1981), págs. 5-22.

Díez Moreno, Fernando, «El control constitucional de la potestad normativa de las Comunidades Autónomas», en Trib. Cons., I, págs. 695-732.

- «La eficacia derogatoria de la Constitución respecto de la legislación constitucional», en $A J \mathrm{~V}$ (1981), págs. 69-90.

FERNÁNDEZ RoDRíguEZ, Tomás Ramón, «La declaración de inconstitucionalidad de las leyes y sus diversas vías», en BDDP (UNED), 5 (1981), págs. 51-61.

- Las leyes orgánicas y el bloque de la constitucionalidad. En torno al artículo 28 de la Ley Orgánica del Tribunal Constitucional, Madrid, Cívitas, 1981.

Lucas Murillo de la Cueva, Pablo, «El examen de la constitucionalidad de las leyes y la soberanía parlamentaria», en REP, 7. (1979), págs. 197-225.

MaRTínez LAFUENTE, Antonio, «Ley de presupuestos e inconstitucionalidad», en Trib. Cons., II, págs. 1711-1763.

Mendizábal Állende, Rafael de, «El control de las disposiciones normativas de las Comunidades Autónomas», en Const. esp. Fuent., págs. 1435-1468.

Parejo Alfonso, Luciano, «La Constitución y las leyes preconstitucionales. El problema de la derogación y la llamada inconstitucionalidad sobrevenida», en $R A P$, 94 (1981), págs. 201-224.

Pastor Ridruejo, Luis, «Aplicación de la ley y control de constitucionalidad», en Trib. Cons., III, págs. 1995-2032.

PÉrez Gordo, Alfonso, «La inconstitucionalidad de las leyes en el arbitraje», en B. Asoc. Esp. Arbitraje; 3 (1981), págs. 32-43. También en Estudios de Derecho Procesal, Zaragoza, 1981, págs. 405-420.

PÉrez Royo, Javier, «La regulación de algunos aspectos del recurso de inconstitucionalidad: su influencia sobre la naturaleza del Tribunal Constitucional en la Constitución española de 1978», en Trib. Cons., III, págs. 2181-2203.

Piqueras Bautista, José Antonio, «La infracción de los reglamentos de las cámaras y la inconstitucionalidad», en Trib. Cons., III, págs. 2205-2227.

Prieto SANChis, Luis, «La protección de los derechos fundamentales a través de los procedimientos de declaración de inconstitucionalidad», en $A D H$ I (1981), pág. 369.

Remiro Brotons, Antonio, «La constitucionalidad de los tratados internacionales y su control por el Tribunal Constitucional», en Trib. Cons., III, págs. 2229. 2267.

Rodríguez Molero, Al., «E1 alcance de la inconstitucionalidad», en RPS, 126 (1980), págs. 109-136.

RoDríguez-ZAPATA Y PÉREZ, Jorge, «Los tratados internacionales y los controles de constitucionalidad», en Trib. Cons., III, pág. 2361. También REDA, 30 (1981), págs. 471-504.

Rubio Llorente, Francisco, «Enunciados aparentemente vacíos en la regulación 
constitucional del control de constitucionalidad», en REP, 7 (1979), págs. 161169.

Sevilla ANDRÉs, Diego, «El control constitucional en una sociedad pluralista», en Trib. Cons., III; págs. 2539-2548.

Soares Manso Preto, José Alfredo, «La fiscalización de la constitucionalidad de las leyes», en Trib. Cons., III, págs. 2549-2583.

Sosa WAGNer, Francisco, «El control de las CC. AA. por el Estado en la Constitución española», en Libro bomenaje al profesor Juan Galván Escutia.

\section{Cuestión de inconstitucionalidad}

González Pérez, Jesús, «La cuestión prejudicial de inconstitucionalidad», en Trib. Cons., II, págs. 1218-1238.

LoRENTE HURTADo, Fernando, «Inadmisión en la cuestión de constitucionalidad y ámbito jurisdiccional ordinario», en La Ley, núm. 215, julio 1981.

PÉrez Gordo, A., «La legitimación activa de las partes en la cuestión de inconstitucionalidad, en $R J C, 3$ (1980).

- Prejudicialidad penal y constitucional en el proceso civil, Barcelona, Bosch, 1982; 309 págs.

- «Problemática procesal de la promoción por los órganos judiciales de la cuestión de inconstitucionalidad», en Trib. Cons., III, págs. 2119-2168. También RDPI XXVII (1) (1981), págs. 85-128, y en Estudios de Derecho procesal, Zaragoza, 1981, págs. 421-461.

Rodríguez Oliver, José María, «Sobre los efectos no suspensivos de la cuestión de inconstitucionalidad y la Ley Orgánica 2/1979, de 3 de octubre», en REDA, 25 (1980), págs. 207-222.

Sala Arquer, José Manuel, «Consideraciones sobre la cuestión de inconstitucionalidad», en Trib. Cons., III, págs. 2445-2464.

\section{Conflictos de competencia}

Alvarez Conde, Enrique, «El Tribunal Constitucional y los conflictos entre las Comunidades Autónomas», en RPC, 3 (1980-81), págs. 123-136. También en Trib. Cons., I, págs. 461-485.

BERMEJo VERA, José, «Cauces para la solución de los conflictos competenciales», en $D A, 182$ (1979), págs. 195-220.

- «La función resolutoria de los conflictos jurisdiccionales», en REDA, 26 (1980), págs. 349-366.

- «La función resolutoria de los conflictos constitucionales negativos por parte del Tribunal Constitucional», en Trib. Cons., I, págs. 575-602.

ESEVERRI, Ernesto, «Competencias legislativas de las comunidades en materia tributaria. Una posible causa de conflictos de competencias», en Trib. Cons., I, págs. 927-957.

Esteban Gómez, José Carlos, «Cuestiones de competencia», en La Ley, núm. 137, abril 1981.

FERnÁndez Rodríguez, Tomás Ramón, «Los conflictos competenciales entre el Estado y las Comunidades Autónomas. Sus reglas de fondo», en Trib. Cons., II, págs. 1093-1109.

- «Reflexiones en torno al artículo 161.2 de la Constitución», en BDDP (UNED), 3 (1979), págs. 7-15.

Leguina VILLA, Jesús, «Los territorios históricos vascos: poderes normativos y conflictos de competencias», en REDC I (3), (1981), págs. 63-92. 
LÓPEZ RODó, Laureano, «El orden de competencia establecido en la Constitución: origen de los conflictos entre el Estado y las Comunidades Autónomas», en Trib. Cons., II, págs. 1457-1481.

Martín Queralt, Juan, «Fiscalidad y conflictos constitucionales positivos de competencia entre Comunidades Autónomas», en Trib. Cons., II, págs. 1641-1666.

MARTín-RETORTILLO BAQUER, Lotenzo, «Conflictos constitucionales de competencia $\mathrm{y}$ de atribuciones», en Trib. Cons., I, págs. 211-252.

MoLAS, I., «Els controls dels órgans de l'Estat sobre las Comunitats Autonomas», en $A P, 3$ (1980), págs. 30-49.

Serrera Contreras, Pedro Luis, «Las Comunidades Autónomas y las impugnaciones del artículo 161.2 de nuestra Constitución», en Trib. Cons., III, págs. 25192537.

Tolivar Alas, Leopoldo, «Un supuesto excepcional de control: el número 2 del artículo 161 de la Constitución española», en Trib. Cons., III, págs. 26612679.

\section{Protección de derechos fundamentales y libertades puiblicas}

AgUtAR DE LuQue, Luis, «Los derechos fundamentales en las relaciones entre privados. Estado de la cuestión», en $A J \mathrm{X}$ (1981), págs. 5-13.

- «Las garantías constitucionales de los derechos fundamentales en la Constitución española», en RDP (UNED), 10 (1981), págs. 107-132.

Almagro Nosete, José, «Cuestiones sobre legitimación en el proceso constitucional de amparo», en RDP (UNED), 10 (1981), págs. 77-106. También en Trib. Cons., I, págs. 369-408.

- «La evolución del derecho a la jurisdicción constitucional», en RDPI, 4 (1981), págs. 579-602.

- «Legitimación y amparo constitucional», en RDPI, 4 (1980), págs. 615-647.

Calvo Caravaca, Alfonso Luis; y Castillo Rigarbert, Fernando, «El extranjero ante el recurso constitucional de amparo», en La Ley, núm. 397, abril 1982.

Cascajo Castro, José Luis, «Appunti sulla tutela dei diritti fondamentali», en Cost. Dem. Spag., 1978, págs. 229-243.

Castedo Alvarez, Fernando, «El recurso de amparo constitucional», en Trib. Cons., I, págs. 179-208.

Domínguez Martín, S., «El recurso de amparo y el Tribunal Constitucional», en $B I M J, 5$ diciembre 1978.

EmbID Irujo, Antonio, «E1 Tribunal Constitucional y la protección de las libertades públicas en el ámbito privado", en REDA, 25 (1980), págs. 191-206. También en Trib. Cons., I, págs. 901-926.

FAtRÉN Gillén, Víctor, «El procedimiento preferente y sumario y el recurso de amparo en el artículo 53.2 de la Constitución», en RAP, 89 (1979), págs. 207249.

Fix Zamudio, Héctor, «El derecho de amparo en México y en España: su influencia recíproca», en $R E P, 7$ (1979), págs. 227-267.

Friginal Fernández-Villaverde, Luis, «Aproximación a una tesis articuladora de los recursos de amparo y contencioso-administrativo», en Trib. Cons., III, páginas 1111-1142.

García Manzano, Pablo, «Las vías judiciales previas al recurso de amparo constitucional», en Trib. Cons., II, págs. 1143-1170.

García Rưz, José Luis, El recurso de amparo en el Derecho español (con un apéndice de P. Pérez Temps: el recurso de amparo en la Constitución de 1978), Madrid, Editora Nacional, 1980. 
Gerpe Landin, Manuel, «El recurso de amparo constitucional», en RJC, 2 (1982), págs. 207-214.

JIMÉnEZ HernándeZ, José Ignacio, «E1 recurso de amparo constitucional respecto de resoluciones judiciales», en Trib. Cons., II, págs. 1309-1327.

LA PÉrgolA, A., «Le garantie giurisdizionali della Costituzione», en La Costituzione Spagnola nel trentennale de la Costituzione italiana, Bolonia, Arnaldo Forni, 1978, págs. 31-48.

LINDE PANIAGUA, Enrique, «Amparo ordinario, amparo constitucional y convención europea para la protección de los derechos humanos y de las libertades fundamentales», en Trib. Cons., II, págs. 1357-1431.

- «Protección de los derechos fundamentales y libertades públicas en la Constitución española de 1978», en RGLJ LXXXII (5), (1981), págs. 469-504.

Martín Rebollo, Luis, «La vía judicial previa al recurso de amparo constitucional», en Trib. Cons., II, págs. 1667-1709.

Martín-Retortillo Baquer, Lorenzo, «Protección y garantía de los derechos y libertades en el Anteproyecto de Constitución», en Autonomía y autogobierno de la Universidad y otros temas, Zaragoza, 1980.

MARTíneZ-SimanCAS Y SÁNCHEZ, Júlián, «La ejecución del acto de los poderes públicos en el recurso de amparo constitucional», en Trib. Cons., II, págs. $1765-$ 1783.

Medina Rubio, Ricardo, «La idea de amparo y el principio de subsidiariedad», en Trib. Cons., II, págs. 1823-1847.

Miguel Zaragoza, Juan de, «La función del Tribunal Constitucional en la interpretación y aplicación de la Convención Europea de Derechos del Hombre», en Trib. Cons., II, págs. 1849-1874.

Montoro Puerto, Miguel, «La alternativa Defensor del Pueblo-Ministerio Fiscal en la garantía jurisdiccional de derechos fundamentales y libertades públicas en España», en RICA, 1 (1980), págs. 48-60.

- «Defectos subsanables y motivos de inadmisión en el proceso de amparo constitucional», I y II, en BIMJ, 1242, págs. 3-11; 1243, págs. 3-15.

- «Garantías jurisdiccionales de los derechos fundamentales y libertades públicas», en Lib. Hom. Juan Galván Escutia, 1980, págs. 455-477.

Peces-Barba, Gregotio, Derechos fundamentales, Madrid, Latina Universitaria, 1980.

Pera Verdaguer, Francisco, «Violación de derechos y libertades por órganos judiciales», en Trib. Cons., III, págs. 2095-2117.

PÉrez Tremps, Pablo, «El recurso de amparo en la Constitución de 1978», en apéndice a El recurso de amparo en el Derecho español, de J. L. García Ruiz, Madrid, 1980, págs. 275-294.

- «El sistema español de los derechos fundamentales y la práctica del Tribunal Constitucional», en $A D H$, I (1981), pág. 423.

Quadra-SAlCEDo, Tomás, El recurso de amparo y los derecbos fundamentales en las relaciones entre particulares, Madrid, Cívitas, 1981.

Salas Hernández, Javier, «Protección judicial ordinaria y recurso de amparo frente a violaciones de libertades públicas», en $R E D A, 27$ (1980), págs. 553-562. También en Trib. Cons., III, págs. 2465-2481.

Salas Hernández, Javier, y Tornos Mas, J., «Comentarios a la Ley de Protección Jurisdiccional de los derechos fundamentales de la persona», en $R A P, 93$ (1980), págs. 29-65.

SÁNCHEZ Agesta, Luis, «El artículo 24 de la Constitución y el recurso de amparo», en Trib. Cons., III, págs. 2483-2496.

Solchaga Loitegui, Jesús, «La legitimación en el recurso de amparo», en Trib. Cons., III, págs. 2585-2631. 